\title{
EREBEA
}

Revista de Humanidades

y Ciencias Sociales

Núм. 6 (2016), pp. 109-145

ISSN: 0214-0691

\section{Cervantes, Scott y el héroe Quijotesco Decimonónico}

\author{
Pedro Javier Pardo García \\ Universidad de Salamanca
}

\section{RESUMEN}

Este trabajo se ocupa de la metamorfosis que Walter Scott opera sobre la figura quijotesca para transformarla en un tipo recurrente en la narrativa decimonónica europea, pues está vinculado a una de sus variantes más características, el bildungsroman. Tal metamorfosis se produce en Waverley, or 'tis Sixty Years Since (1814), por lo que, en primer lugar, se analizan los rasgos quijotescos distintivos del nuevo tipo de héroe que Scott formula en esta novela: su imaginación romántica de raíz literaria y su inadecuación a un modelo heroico de carácter caballeresco. A continuación, se estudia la inserción de tal quijotismo en un relato de aprendizaje y desilusión para, finalmente, mostrar cómo el héroe quijotesco que cristaliza en Wavelery dará lugar a un tipo de relato que podemos denominar la novela del héroe fallido. El héroe quijotesco decimonónico es resultado de las transformaciones que Scott y otros autores efectúan no solo sobre el original español sino también sobre sus metamorfosis extranjeras posteriores.

\section{Palabras Clave}

Walter Scott; Waverley; quijotismo; bildungsroman; héroe fallido.

Fecha de recepción: 8 de nov. de 2016 Fecha de aceptación: 30 de nov. de 2016
ABSTRACT

This essay deals with the metamorphosis operated by Walter Scott on the quixotic figure, which turns him into a recurring type in nineteenth-century European narrative, since it is associated with one of its most distinctive kinds, the bildungsroman. This metamorphosis takes place in Waverley, or 'tis Sixty Years Since (1814), so, in the first place, the quixotic features of the new type of hero formulated by Scott in this novel are examined: his romantic imagination rooted in literature and his unsuitability for a heroic role of chivalric origins. Then, the essay explains how this quixotism is immersed in a narrative of apprenticeship and disillusionment, and, finally, how the quixotic hero which emerges in Waverley will give rise to a kind of narrative which is described as the novel of the failed hero. The nineteenth-century quixotic hero is the result of the transformations that Scott and other authors implement not only on the original Spanish model but also on its later foreign metamorphoses.

\section{KeYwords}

Walter Scott; Waverley; quixotism; bildungsroman; failed hero. 

Desde que en 1838, tan solo seis años después de la muerte de Walter Scott, se publicara en Lund un breve estudio de no más de veinte páginas que lleva por título Cervantes et Scott: parallèle litteraire, obra del profesor, lingüista y traductor de Shakespeare al sueco Carl August Hagberg (Charles Auguste en la portada), son muchos los estudiosos que han constatado este paralelismo y se han ocupado de investigarlo. De la inspiración que Scott encontró en Cervantes desde el arranque de su carrera hasta el final de sus días dio testimonio Bell, un testimonio reciclado hasta la saciedad por todos los que después se han ocupado del tema, aunque fue Wolfe en un artículo de ese mismo año quien materializó la relación entre ambos en un exhaustivo inventario de referencias cervantinas (más de cien solo a Don Quijote) en los escritos de Scott (no solo en sus novelas, sino también en ensayos, diarios y correspondencia), que además amplía con las que hace a otras obras literarias espańolas o con las abundantes citas de palabras, frases o refranes en español ${ }^{1}$. De la interpretación y comentarios que hizo Scott del Quijote, muy importante para traducir esa admiración acreditada por las referencias en influencia efectiva y constatable por analogías, dio buena cuenta McDonald ${ }^{2}$. Y son precisamente tales analogías las que han centrado la atención de los investigadores en las últimas décadas. Wolpers, Müller y Müllenbrook se han centrado en las que afectan a personajes, especialmente las concomitancias que Don Quijote guarda con el protagonista de Waverley. ${ }^{3}$. Gaston, Horst y Gerli han buceado en las afinidades generales en la concepción y la práctica novelística de ambos autores, un

1 Aubrey Bell, "Scott and Cervantes", en H. J. C. Grierson (ed.): Sir Walter Scott Today: Some Retrospective Essays and Studies. London: Constable, 1932, especialmente pp. 69-70; y Clara Snell Wolfe, "Evidences of Scott Indebtedness to Spanish Literature", en The Romanic Review, vol. 23, no 4 (1932), pp. 301-311.

2 W. U. McDonald, "Scott's Conception of Don Quixote", en Midwest Review, vol. 1 (1959): pp. 37-42.

3 Theodor Wolpers, "Der romantische Leser als Kriegheld und Liebhaber: Poetisierung der Realität in Walter Scotts Waverley", en Theodor Wolpers (ed.): Gelebte Literatur in der Literatur. Studien zu Erscheinungsformen und Geschichte eines literarischen Motivs. Göttingen: Vandenhöck, 1986, pp. 185-197; Wolfgang Müller, "Sir Walter Scotts Waverley und die Don Quijote-Tradition", en Arcadia, vol. 23 (1988), pp. 133-148; y Heinz Joseph Müllenbrook, "Scotts Waverley als ,Respons' auf Cervantes's Don Quixote", en Literaturwissenschaftliches Jahrbuch im Auftrage der Görres Gesellschaft, vol. 40 (1999), pp. 139-54 (revisado como "Genre-Making by Transforming Tradition. The Case of Walter Scott's Waverley: A Complementary Perspective", en Der historische Roman, Aufsätze. Heidelberg: Carl Winter, 2003, pp. 80-93). 
camino ya apuntado en el integralismo de Bell ${ }^{4}$. Alfredo Moro, quien está llamado a convertirse en la referencia indiscutible sobre el tema, se ha ocupado de ambas cuestiones, la última en un artículo sobre el cervantismo de Scott en Waverley y la primera en un trabajo en prensa sobre diferentes tipos de quijotismo discernibles en las primeras novelas de Scott 5 .

No es mi intención repetir los argumentos ya esgrimidos por mis predecesores, sino centrarme en lo que me parece la aportación más original de Scott en el seno de la tradición cervantina, es decir, a la luz de la manera en que autores previos y posteriores a él leen y utilizan el ejemplo cervantino; y en el ámbito del mito y no del método, utilizando la sabia distinción de Welsh que ya hemos seguido al revisar los estudios sobre Cervantes y Scott, es decir, en la reescritura de un personaje o situación narrativa que da lugar al mito quijotesco y no en la imitación de una concepción de la novela que es el método cervantino ${ }^{6}$. Dentro de este ámbito, nos interesa la metamorfosis que Scott opera sobre la figura quijotesca para transformarla en un tipo que se convertirá en recurrente en la narrativa decimonónica, pues está vinculado a una de sus variantes más características, el bildungsroman, en sus diferentes modulaciones y transformaciones. Tal metamorfosis se produce de manera paradigmática en Waverley, or 'tis Sixty Years Since (1814), la primera novela publicada por el hasta entonces poeta Walter Scott (1771-1832), con la que arrancó una prolífica carrera de novelista en la que produciría más de una veintena de volúmenes conocidos como las Waverley Novels. No es de extrańar que sea su primera novela la que se acoge de forma más explícita a la tutela de Cervantes y en la que el patrón quijotesco es más evidente, antes de que lo desarrolle en otras direcciones y de que el oficio y el éxito lo lleven por otros caminos. Pero no es Don Quijote su única referencia, pues algunas discontinuidades que se

4 Patricia Gaston, “The Waverley Series and Don Quixote: Manuscripts Lost and Found", en Cervantes, vol. 11 (1991), pp. 45-59; Robert ter Horst, "Effective Affinities: Walter Scott and Miguel de Cervantes", en Francisco la Rubia Prado (ed.): Cervantes for the 21 $1^{\text {st }}$ Century/Cervantes para el siglo XXI. Studies in Honor of Edward Dudley. Newark, Delaware: Juan de la Cuesta, 2000, pp. 199-219; y E. Michael Gerli, "Pray landlord, bring me those books': Notes on Cervantes, Walter Scott and the Ethical Legitimacy of the Novel in Early Nineteenth Century England", en Michael J. McGrath (ed.): Corónente tus hazañas: Studies in Honor of John Jay Allen. Newark, Delaware: Juan de la Cuesta, 2005, pp. 231-243.

5 Alfredo Moro, "Cervantismos olvidados: Sir Walter Scott", en Emilio Martínez Mata y María Fernández Ferreiro (eds.): Comentarios a Cervantes. Oviedo: Fundación María Cristina Masaveu Peterson, 2015, pp. 300-310; y "Sir Walter Scott y la literatura europea: el ejemplo de Cervantes y de la tradición cervantina”, en 1616 (en prensa). Agradezco a Alfredo Moro el haberme permitido consultar su trabajo antes de su difusión impresa, así como su honestidad intelectual al citar en el mismo este artículo mío como una de las fuentes que ha manejado, pues, efectivamente, este texto fue escrito en su mayor parte hace años, pero una serie de azares han aplazado su publicación hasta ahora.

6 Alexander Welsh, "The Influence of Cervantes", en Anthony Cascardi (ed.): The Cambridge Companion to Cervantes. Cambridge: Cambridge University Press, 2002, pp. 81-99. 
aprecian con Cervantes son explicables por los cambios operados sobre el modelo quijotesco por autores previos de la tradición cervantina. Ello pone de manifiesto, una vez más, que la reescritura del mito quijotesco por un autor determinado rara vez es un asunto de pareja, como sugiere el enfoque binario y basado en la influencia que han seguido la mayoría de los estudios citados más arriba. Se trata, más bien, de una relación a tres y hasta a más bandas que exige un enfoque intertextual y transnacional de la tradición cervantina más allá de Cervantes.

\section{La IMAginación Romántica}

El lector de Waverley no tiene que esperar mucho para descubrir el pedigrí quijotesco de su protagonista y las credenciales cervantinas de su autor. Apenas iniciado el relato con la descripción de los antecedentes familiares de Edward Waverley, el narrador se centra en su educación, dirigida tanto por su padre biológico, Richard, como por su tío y padre putativo, Sir Everard, quienes mantienen posiciones políticas y visiones de mundo enfrentadas. La consecuencia inmediata de esta dualidad es que a Edward se le permite "to learn as he pleased, what he pleased, and when he pleased"7. En este contexto de desregulación, agravado por la temprana muerte de su madre, la lectura va a ocupar una posición central en su formación y en su vida, pero practicada como pasatiempo y con un carácter errático, fruto tanto de la negligencia de su familia e indulgencia de sus tutores como de una mente indolente pese a su inteligencia: "With a desire of amusement therefore, which better discipline might soon have converted into a thirst for knowledge, young Waverley drove through the sea of books, like a vessel

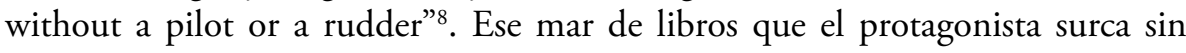
rumbo se describe con detalle a través de la enumeración de los volúmenes de la bien nutrida biblioteca de Waverley-Honour, en la que Edward da rienda suelta a su pasión literaria sobre todo por textos de carácter romántico y caballeresco, una inclinación que también alimentan los relatos sobre las aventuras heroicas de sus ancestros narrados tanto por sus tíos como por crónicas históricas?

7 Walter Scott, Waverley, Peter D. Garside (ed.). London: Penguin, 2011, I, ii, p.12. Cito siempre por esta edición del texto.

8 Scott, Waverley, I, iii, p.14.

9 Las lecturas de Waverley abarcan no solo la literatura inglesa (Shakespeare, Milton, Spenser, y "other poets who have exercised themselves on romantic fiction", I, iii, p. 15), sino también la clásica y la de las lenguas romances: la italiana, tanto "romantic poems" (término con el que se refiere a la tradición inaugurada por Pulci, al que cita, y que continúan Boiardo, Tasso o Arisoto), como novelle al estilo del Decameron; la francesa, que "had afforded him an almost exhaustless collection of memoirs, scarcely more faithful than romances, and of romances so well written as hardly to be distinguished from memoirs" (p. 15); y la española, que "contributed to his stock of chivalrous and romantic lore" (p. 15). Los relatos familiares tienen la misma índole caballeresca, como prueban las hazañas de Wilibert de Waverley en Tierra Santa (I, iv, p. 17). 
El impacto de estas lecturas en una mente cuya facultad predominante se dice que es la imaginación ${ }^{10} \mathrm{y}$ en un carácter que se presenta como abstraído, visionario y fantasioso (véase el capítulo cuarto, significativamente titulado "CastleBuilding" y donde se le califica de "youthful visionary"), además de solitario, poco sociable y con "a extreme and increasing sensibility added to this dislike of society"11, configuran una personalidad libresca y soñadora ("bookish turn", "waking dreams"12) cuya falta de tutela, instrucción y experiencia del mundo permiten anticipar su deriva quijotesca. Tal quijotismo se formula abiertamente cuando Scott explica por boca de su narrador:

From the minuteness with which I have traced Waverley's pursuits, and the bias which they have unavoidably communicated to his imagination, the reader may perhaps anticipate, in the following tale, an imitation of the romance of Cervantes. But he will do my prudence injustice in the supposition. My intention is not to follow the steps of that inimitable author, in describing such total perversion of intellect as misconstrues objects actually presented to the senses, but that more common aberration from sound judgement, which apprehends indeed occurrences in their reality, but communicates to them a tincture of its own romantic tone and colouring. ${ }^{13}$

Scott apunta la raigambre quijotesca de su personaje evocando el ejemplo cervantino, para acto seguido matizarla afirmando las diferencias de su héroe con el hidalgo manchego. En ambos, la literatura es la fuente de una distorsión epistemológica de la realidad con un similar carácter romántico; pero ahora no se trata de la radical transformación de la misma como resultado de la locura de un viejo que ha perdido la cabeza, sino de una tintura o tono ańadido por la mente imaginativa y fantasiosa de un joven, lo que produce una redefinición del quijotismo como coloración romántica juvenil. En este sentido, aunque sus orígenes sean igualmente librescos, el quijotismo de Edward es modal y no genérico, es decir, no está modelado sobre un género concreto de romance, como el del hidalgo sobre los libros de caballerías, sino que se asienta en el modo romance común a todos ellos, eso que podemos llamar la imaginación romántica ${ }^{14}$. 
El quijotismo del protagonista se observa perfectamente cuando, tras abrazar la profesión de las armas en la que espera brillar como sus ancestros, se incorpora a un regimiento acuartelado en Escocia y pide permiso para ir a conocer el país, primero a Tully-Veolan, la mansión del viejo camarada jacobita de su tío, el Barón de Bradwardine, y luego a las Highlands, al feudo de Fergus MacIvor en Glennaquoich. En esos capítulos que describen su periplo por Escocia, el narrador no se cansa de destacar cómo la imaginación literaria y romántica de Waverley encuentra allí territorio abonado para ejercitarse a placer ${ }^{15}$, aunque tal insistencia pone de manifiesto una cierta distancia, observable de manera muy clara, por ejemplo, cuando el narrador explica las razones por las que el protagonista no siente interés por Rose Bradwardine: su belleza discreta y sus domésticos méritos no responden a las expectativas románticas que de su dama o de sí mismo tiene Edward $^{16}$. Tal distancia es aún más notoria en la forma en que el autor se complace en ir puntuando tales expectativas con el correctivo de la realidad, aunque de forma mucho más sutil que la que utilizaba Cervantes con su caballero. Cuando Edward llega a Tully-Veolan, el silencio reinante le hace pensar en la llegada de Arturo al castillo de Orgoglio en The Faerie Queene ${ }^{17}$, pero el lector aún tiene en mente la descripción previa de las penosas y miserables condiciones de vida en la aldea que acaba de atravesar ${ }^{18}$. Su visión del lugar como locus amoenus, además, se ve truncada por dos rudas y poco pudorosas doncellas que se bañan en el río, en una escena que, como subraya irónicamente el narrador, no resiste comparación con una similar del Orlando Furioso y que se ve coronada por la aparición de la grotesca y alienada figura de Davie Gellatley ${ }^{19}$. Y el mismo patrón rige su primera toma de contacto con las tierras altas escocesas. Cuando Rose le habla por primera vez de estos lugares,

Waverley could not help starting at a story which bore so much resemblance to one of his own day-dreams. Here was a girl scarce seventeen ... who had witnessed with her own eyes such a scene as he had used to conjure up in his imagination as only occurring in ancient times. He felt at once the impulse of curiosity, and the slight sense of danger that only serves to heighten his interest. He might have said, with Malvolio, "I do not now fool myself, to let my imagination jade me.' I am actually in the land of military and romantic adventures, and it only remains to be seen what will be my own share in them." 20

15 Scott, Waverley, pp. 59, 61, 64, 70, 77, 84.

16 Scott, Waverley, I, xiv, pp. 70-71.

17 Scott, Waverley, I, ix, p. 39.

18 Scott, Waverley, I, viii.

19 Scott, Waverley, I, ix, p. 40.

20 Scott, Waverley, I, xv, p. 77 (énfasis añadido). 
El pasaje es sintomático de la visión literaturizada y romantizada que de Escocia tiene Edward; pero también de su quijotismo por la cervantina manera en que tal visión va a dialogar con lo que será su experiencia en esos románticos dominios, empezando por el personaje que le dará la bienvenida a los mismos, el bandido Donald Bean Lean, cuya figura diminuta y ataviada con una casaca militar francesa es "totally different in appearance and manner from what his imagination had anticipated"21.

La novela profundiza en esta tensión entre literatura y vida, imaginación romántica y realidad -más latente que evidente, pues nunca tiene la crudeza de que la dotó Cervantes en su obra- con las vivencias de Waverley en Glennaquoich. Allí efectivamente encuentra no solo el pasado legendario y tribal de sus fantasías literarias (cuyo epítome es el banquete feudal del clan MacIvor), sino también a la mujer que sí encaja perfectamente en sus expectativas románticas: Flora, la hermana de Fergus, "was precisely the character to fascinate a youth of romantic imagination"22. Idilio amoroso y leyenda guerrera convergen en la escena del glen, cuando, "like a knight of romance"23, Edward se deja conducir por la dama a un valle recóndito y salvaje que "seemed to open into the land of romance"24; y donde, al pie de una cascada, la escucha recitar, acompañada de su arpa, un poema legendario de "celtic minstrelsy" (tal es el título del capítulo xxii). Estamos en la apoteosis de la imaginación romántica del héroe, producto del contacto con una heroína como no había podido imaginar ni en sus "wildest dreams" a la que se compara con una encantadora de Ariosto o Boiardo ${ }^{25}$, y de una vieja canción de guerra que evoca y convoca a los héroes y chieftains de los clanes de Escocia; es decir, como efecto de la combinación entre amor y caballería que no puede sino producir en Edward "a wild feeling of romantic delight" 26.

En tal estado de exaltación -o de intoxicación- no es de extrañar que decida prolongar su estancia para asistir a la cacería donde tendrá la oportunidad de ver con sus propios ojos la reunión de muchos de esos clanes de los que habla la canción. Scott, sin embargo, se ocupa de dejar claro que toda esta experiencia no es fruto tanto de la realidad como de un encantamiento romántico de la misma, o sea, de la percepción quijotesca por parte de Edward. Cegado por su visión romántica, el héroe no es consciente de la realidad histórica que se oculta tras ella: Flora está siendo utilizada como cebo por Fergus para atraer a Edward a la causa jacobita y promover así sus ambiciones políticas; el poema es una incitación a la rebelión que de hecho prefigura la que está a punto de producirse; y la cacería no

21 Scott, Waverley, I, xvii, p. 86.

22 Scott, Waverley, II, i, p. 122.

23 Scott, Waverley, I, xxii, p. 112.

24 Scott, Waverley, p. 112.

25 Scott, Waverley, p. 114.

26 Scott, Waverley, p. 115. 
es sino la primera reunión de los rebeldes, tras la que sus líderes acuden a recibir al pretendiente jacobita al trono británico, el príncipe Charles Edward Stuart. Tal ceguera, no tan diferente de la de Don Quijote cuando no ve la realidad sensible que se oculta tras su romántica fantasía, será una constante en la experiencia escocesa de Edward, quien, al ser detenido más tarde por las autoridades británicas, será acusado precisamente de todo eso que no ha visto, pese a haber sido testigo o espectador de ello ${ }^{27}$.

El episodio de la cacería es también sintomático de una dimensión menos obvia del quijotismo de Edward: el ejercicio de su imaginación romántica no solo distorsiona su percepción empírica sino que la sustituye por otra que podríamos denominar estética. Lejos de sentir pesar por abandonar la cacería prematuramente a causa del accidente que sufre, se complace en el "efecto romántico" que le produce esa visión privilegiada de la llanura cubierta con la marea multicolor de todos los clanes de las tierras altas ${ }^{28}$, proporcionada por la posición elevada de la litera en que lo transportan. La ceguera epistemológica va de la mano de una aguda sensibilidad estética, un patrón de conducta que se manifiesta sobre todo en su contemplación del paisaje escocés, como ha indicado acertadamente Kerr cuando apunta el carácter estetizante de su mirada y cómo este hace de su periplo escocés algo muy parecido al de un turista ${ }^{29}$. Esta forma de mirar el paisaje se explicita cuando se comparan los escenarios que desfilan ante la mirada del personaje con cuadros de Claude Lorrain o Salvatore Rosa; pero, en última instancia, está vinculada, como Kerr reconoce, a la imaginación romántica del personaje, que de nuevo funciona de manera quijotesca al convertir la realidad en una obra de arte, tanto literaria como pictórica. Waverley somete el mundo a un proceso de estetización que proyecta una imagen mental de orígenes literarios sobre el mismo

27 Scott, Waverley, II, viii, p.168-69.

28 Scott, Waverley, II, i, p. 125.

29 "Edward Waverley ... is continually making a work of art out of the landscape. Waverley brings to the landscape a taste for the picturesque and the romantic which leads him to transform reality into pictures, to render the world into an occasion for aesthetic experience, as a scene in a painting or a work of literature. The avenue leading to the manor-house becomes a picture which allows the traveller to efface from his mind the sordid details of the village scene. The definitive gesture for Waverley is one of aestheticizing the world outside his imagination, of making pictures as a way of evading reality... What we see here is a romantic imagination acting out his wishes through the medium of the Scottish landscape" (James Kerr, Fiction Against History: Scott as Storyteller. Cambridge: Cambridge University Press, 1989, p. 24, énfasis añadido). Esta forma estetizada de mirar un entorno desconocido pero imaginado es la propia de un turista, que es exactamente como Kerr identifica al Edward que se va de permiso para conocer Escocia, en un periplo que es básicamente el de un viajero que tiene una idea preconcebida de lo que quiere ver y es por ello quijotesco, una figura de la que me he ocupado en "Viajeros quijotescos y viajes cervantinos en las letras británicas", en José Checa Beltrán (ed.): La cultura española en la Europa romántica. Madrid: Visor, 2015, pp. 121-151. 
y cancela aquellos aspectos hostiles a la misma, algo observable en lo concerniente no solo al paisaje sino también a su experiencia escocesa en general ${ }^{30}$.

La condición quijotesca de Edward enunciada en el inicio de la novela se ve así refrendada y desarrollada por la acción de la misma y recibe confirmación al tiempo que colofón en una segunda alusión a Cervantes, ahora en boca de un personaje en vez del narrador. Al volver a Glennaquoich conduciendo a un Waverley maltrecho por un nada heroico accidente en la cacería, MacIvor compara su situación con la de los héroes Valdovinos o Abindarráez conducidos por el marqués de Mantua y Rodrigo de Narváez, descritas en el romance medieval del mismo nombre y en la Historia del Abencerraje y la hermosa Jarifa (1561), respectivamente, tal como hacía el propio Don Quijote al verse maltrecho y recogido por su vecino Pedro Alonso tras el apaleamiento que pone fin a la primera salida ${ }^{31}$. A diferencia de Don Quijote, sin embargo, Fergus utiliza esta comparación de forma burlesca, equiparando así la forma en que tanto Don Quijote como Edward se ven y poniéndose a sí mismo respecto de este en la posición de Cervantes respecto de aquel: "Ah, long rest your soul, Cervantes! without quoting thy romaunts, how should I frame my language to befit romantic ears!" 32 . Naturalmente los románticos oídos a los que Fergus puede adaptar su discurso gracias a Cervantes son los de Edward, cuyo quijotismo es tan visible para aquel como la realidad histórica es invisible para este. La cita cervantina demuestra que McIvor identifica perfectamente el quijotismo de Edward y asume una distancia irónica frente al mismo (como hará más adelante también su hermana Flora), la misma que asume el narrador de Waverley, quien la seguirá ejerciendo cada vez que incida en la imaginación romántica de su héroe en pasajes que, en virtud de la discrepancia irónica entre visión y realidad observable a lo largo de toda la novela, funcionan como recordatorios de su quijotismo ${ }^{33}$. $Y$ así funcionan también otras tres referen-

30 Así lo pone de manifiesto un pasaje sobre el que llama la atención Kerr (Fiction Against History, pp. 31-32), en el que Edward se abandona "to the full romance of his situation": en su travesía de las tierras altas escocesas, cruza un lago, pasada la medianoche, de camino a la morada de un bandido al que compara con Robin Hood y guiado por un desconocido hacia posibles peligros. "What a fund of circumstances to the exercise of a romantic imagination", reflexiona Edward, para añadir a continuación: "The only circumstance which assorted ill with the rest was the cause of his journey-the Baron's milk cows! This degrading incident he kept in the back-ground" (Scott, Waverley, I, xvi, p. 84). La realidad socioeconómica, en este caso los conflictos históricos entre las formas de vida de las tierras altas y bajas escocesas representados por las vacas robadas al Barón, rompe el hechizo del cuadro que Waverley pinta en su imaginación, por lo que este la relega al fondo del mismo, donde no interfiere con su fantasía.

31 Scott, Waverley, I, v. Puede encontrarse una explicación detallada de las resonancias y referentes literarios de esta cita cervantina en al artículo citado de Horst ("Effective Affinities...", pp. 205-206).

32 Scott, Waverley, II, i , p. 128.

33 De los muchos pasajes que se pueden citar a este respecto (vid. Scott, Waverley, pp. 139, $173,176,178,193)$, merece la pena detenerse en uno en que el narrador explica el proceso de ide- 
cias a Cervantes menos significativas que aparecen más adelante en el volumen segundo y tercero de la obra ${ }^{34}$.

Tales volúmenes no ańaden mucho a este quijotismo del héroe que ha quedado ya perfectamente establecido en el primero, entre la primera alusión cervantina del capítulo quinto y esta segunda del primer capítulo del segundo volumen. Ello es lógico si tenemos en cuenta que tal quijotismo juega un papel determinante en la decisión de abrazar la causa jacobita que da el giro decisivo a su vida y a la novela, aunque, como ha puesto de manifiesto Müllenbrook siguiendo a Müller (en los artículos ya citados), en tal decisión juega también un papel importante el pasado jacobita de su familia y por tanto las tensiones políticas y el contexto histórico de la época. Ello, sin embargo, no significa que debamos menospreciar la importancia que la imaginación romántica y literaria tiene en la trayectoria del héroe y que su quijotismo sea secundario por estar supeditado en última instancia al proyecto de creación de la novela histórica moderna ${ }^{35}$. Nos parece preferible verlo más que subordinado como perfectamente integrado en tal proyecto, y en

alización romántica de Flora en términos que vienen a equipararla con la Dulcinea quijotesca: "All that was common-place, all that belonged to the every-day world, was melted away and obliterated in these dreams of imagination, which only remembered with advantage the points of grace and dignity that distinguished Flora from the generality of her sex, not the particulars which she held in common with them. Edward was, in short, in the fair way of creating a goddess out of a high-spirited, accomplished, and beautiful young woman; and the time was wasted in castle-building until..." (Scott, Waverley, II, vi, p. 152, énfasis añadido).

34 Scott, Waverley, II, xiii, p. 209, III, x, p. 284 y III, xi, p. 286.

35 En este respecto discrepamos de Müllenbrock, quien, aun reconociendo el quijotismo del protagonista, enfatiza su carácter subsidiario y sus diferencias respecto a la tradición quijotesca inglesa previa, vinculando la peripecia de Waverley no a sus lecturas y temperamento romántico, sino a los condicionantes de su entorno, especialmente su familia, educación y circunstancias, esas fuerzas de la historia que Scott pretende representar y a la que se subordinaría lo quijotesco. Desde nuestro punto de vista, por el contrario, el quijotismo es la piedra angular sobre la que se construye la personalidad de Waverley, sobre la que descansa la decisión de sumarse a la rebelión jacobita, que es la más trascendente de su vida y el centro de la novela, pues su quijotismo es el sustrato en el que convergen y sobre el que actúan los factores desencadenantes de esa decisión misma: el jacobitismo familiar que le incita a abandonar el ejército inglés y lo pondrá al margen de la ley va unido a la nostalgia del pasado que es una constante de la experiencia quijotesca; su amor por la jacobita Flora MacIvor tiene ese carácter quijotesco que convierte a una mujer en una heroína romántica y crea una Dulcinea; y la causa jacobita tiene un halo caballeresco bien encarnado por su líder, the Young Chevalier, quien, recién llegado a Edimburgo, le pide que se una a ella de forma irresistible para Edward porque el pretender se ajusta perfectamente a la idea de un hero of romance (Scott, Waverley, p. 206). Es su quijotismo, entendido tal como acabamos de describir y presente en estos factores, lo que le hace abrazar la causa jacobita, aunque sea de forma pasiva y como fruto de maquinaciones ajenas y de la encrucijada histórica en que se encuentra. Además, el hecho de que tal quijotismo sea diferente tanto del original cervantino como de sus antecedentes cervantinos ingleses por esa inmersión en la historia no lo cuestiona en absoluto, como argumenta Müllenbrook, pues las diferencias son la norma en la dinámica reescritural que también puede reconocerse en esos antecedentes citados por el estudioso alemán. 
ello incide el desarrollo de tal quijotismo a partir de esa resolución de unirse a los rebeldes, que da inicio a unas aventuras que ya no serán solo amorosas sino también militares. En ellas Edward no hace sino buscar las caballerias que lo transformen en un héroe romántico como los de las lecturas que pretende emular. Lo que encontrará, sin embargo, será una segunda dimensión de su quijotismo que no es tan evidente pero que es tan importante como la romántica, y que hará de él un héroe quijotesco en un sentido nuevo y desconocido en la tradición cervantina no solo inglesa sino europea.

\section{LA INADECUACIÓN HEROICA}

El quijotismo de Edward Waverley supone un salto evidente en relación a la concepción cervantina del mismo, pero no es tan original como pueda parecer inicialmente a un lector no familiarizado con la literatura inglesa, pues tiene su precedente en algunas de las figuraciones quijotescas a las que Don Quijote había dado lugar en el siglo XVIII, concretamente -como ha puesto de manifiesto Duncan- en los quijotes femeninos: "Edward Waverley is less like Don Quixote, who rides out to force his vision on the world, than the generic type of eighteenth-century romance reader, the female quixote, whose imagination suspends her from intercourse with society" ${ }^{36}$. El sujeto quijotesco de Scott es, en efecto, una masculinización de la heroína patentada por Charlotte Lennox en The Female Quixote (1752), con la que comparte la concepción del quijotismo como los excesos de una imaginación romántica fruto de la lectura pero también de la juventud, la inexperiencia y el aislamiento, además de ciertos rasgos secundarios ligados a tal concepción: la orfandad que crea un vacío educativo subsanado en la biblioteca, donde encuentra no solo la literatura romántica que moldea su visión de mundo sino un espacio de enclaustramiento y retiro que orienta su personalidad hacia la introversión y el ensueño en vez de la acción. Ello crea otro notorio paralelismo con el quijotismo femenino, la pasividad, que en el caso de las mujeres quijote era en gran medida resultado de la obligada constricción de la mujer al ámbito doméstico por parte de la sociedad patriarcal de la época. Por ello, la transferencia a la esfera masculina por parte de Scott hace esa pasividad e introversión más llamativas, llegando a convertirlas en cierta y abiertamente in-

36 Ian Duncan, Modern Romance and Transformations of the Novel: The Gothic, Scott, Dickens. Cambridge: Cambridge University Press, 1992, p. 63. Duncan añade: "Waverley narrates the sentimental education of a young man who starts off as a female quixote and encounters Gothic lures and perils in his traversal of the field of history" (p. 13). Duncan desarrolla ciertos aspectos de esta comparación en el capítulo segundo de su libro (especialmente pp. 63-73) y, de forma sintética, vuelve a enunciarla en su introducción a la novela: "The early chapters establish Waverley as a masculine version of the Female Quixote ... rather than a modern Don Quixote - reading purely, passively, for pleasure, not for action, in a narcissistic trance", Introduction, Waverley, London: Penguin, 2011, p. xxv). 
congruentes al sumergir al sujeto quijotesco en una acción heroica que exige de él su participación activa y decidida, lo que acaba poniendo de manifiesto su inadecuación o incapacidad para la misma. Waverley recupera así algo de la dimensión antiheroica del quijotismo ausente en la mujer quijote (cuyas cualidades suelen ponerla a la altura de las heroínas que imita) y vuelve por esta inesperada vía al modelo quijotesco original del que se alejaron sus avatares femeninos.

No es necesario insistir demasiado en la pasividad de Edward, pues ya Alexander Welsh en su estudio clásico sobre el héroe de las Waverley novels la identificó como su cualidad definitoria: estas suelen girar en torno a un personaje inactivo e indefenso, víctima de los acontecimientos y de la actividad de otros agentes, pero que ocupa el centro de un relato en el que al final obtiene recompensa, héroe por tanto solo en el sentido de protagonista y no por su estatura heroica, cuya ausencia además se subraya mediante el contraste con personajes que sí la poseen pero que no son los protagonistas ${ }^{37}$. De ello tenemos pruebas en Waverley desde el inicio mismo de la experiencia escocesa de Edward por la forma en que este reacciona a la ofensa del Laird de Balmawhapple durante el banquete ofrecido en su honor por el Barón de Bradwardine, a la que responde su anfitrión batiéndose en duelo con aquel y obligándolo a disculparse sin que el protagonista se entere de ello. La misma pasividad se observa en la decisión más trascendente de su vida, la de unirse a la causa jacobita, que es fruto de una serie de accidentes y de maquinaciones ajenas, como él mismo percibe al verse como un juguete de circunstancias que no control y como detecta también la propia Flora ${ }^{38}$; y a la que llega, además, tras una serie de dudas y vacilaciones que se prolongan después de haberla tomado, especialmente durante la campaña militar, cuando ve morir a uno de sus hombres en el regimiento inglés, se siente responsable y se interpela en términos que no dejan lugar a dudas sobre este aspecto de su carácter: "O indolence and in-

37 Alexander Welsh, The Hero of the Waverley Novels. With New Essays on Scott. Princeton, NJ: Princeton University Press, 1992 (1963). Los personajes de Scott, explica Welsh, están limitados en su capacidad de acción por los ideales que representan, que no son los del héroe del romance medieval o caballeresco al que tanto al autor como sus personajes son tan aficionados, sino los del hombre de leyes que era Scott, a saber, la prudencia, la autoridad, el respeto a la propiedad y a la ley que es su garante, y todos los demás ideales sociales que rigen la vida civilizada de la modernidad posrevolucionaria. "The hero of civilization and refinement is a passive hero of 'quiet and retiring' character" (p. 18), sentencia Welsh; o, tal y como se describe perfectamente a sí mismo uno de estos héroes, ".... mere victim of ... events, ... a thing never acting but perpetually acted upon..., as passive and helpless as a boat that drifts without oar or rudder at the mercy of the waves and winds" (p. 22). Tal descripción apunta a la plena conciencia de Scott de esta pasividad, que corrobora la reseña que escribió y publicó de forma anónima en 1817 de sus Tales of My Landlord: "Waverley, Brown, or Bertram in Guy Mannering, and Lovel in The Antiquary, are all brethren of a family; very amiable and very insipid sort of young men ... His chief characters are never actors, but always acted upon by the spur of circumstances, and have their fate uniformly determined by the agent of subordinate persons..., the passive tool of the other characters" (p. 34).

38 Scott, Waverley, II, iv, p.141-142 y p. 144. 
decision of mind"39. Y los mismos factores externos o ajenos a su voluntad que lo empujan por el proceloso camino de la sedición lo salvan al final de sus peligrosas consecuencias: son los buenos oficios el coronel Talbot, pero también del mayor Melville y el reverendo Morton, y no sus propios esfuerzos, los que consiguen el perdón final. En resumen, son siempre otros los que ponen en y sacan de apuros al protagonista, como cuando es hecho prisionero por desertor pero es rescatado por la partida de Donald Bean (con la ironía adicional de que es Rose quien ha promovido esta expedición de rescate), una acción durante la cual, como ocurrió en la cacería, es herido y cae enfermo, por lo que hay que transportarlo primero y luego detener la expedición para cuidarlo. Este episodio es el clímax del papel femenino que desempeña Edward en sus propias aventuras: su posición de objeto pasivo y el misterio que envuelve el rescate lo asemeja a los secuestros que sufren a menudo las heroínas tanto románticas como quijotescas, desde la de Pamela de Richardson (1740), pasando por la Arabella de Lennox, hasta las del género gótico de finales de siglo, a todas las cuales podría aplicarse perfectamente la reflexión del propio Edward a propósito de "the strangeness of his fortune, which seemed to delight in placing him at the disposals of others, without the powers of directing his own motions" ${ }^{\prime 4}$.

En efecto, si de la tradición iniciada por The Female Quixote Edward hereda la juventud, la imaginación romántica y la educación a través de la lectura en una biblioteca, con las heroínas góticas, especialmente las de Radcliffe, comparte el carácter modal y no genérico de su imaginación romántica, su proyección estética -o turística- sobre los lugares visitados y, sobre todo, su actividad más intelectual que física, la creación de imágenes más que la ejecución de actos ${ }^{41}$. Pero la pasividad de esta nueva figuración quijotesca no solo tiene modelos femeninos, sino que también lo entronca con algunos ilustres precedentes prerrománticos,

39 Scott, Waverley, II, xxii, p. 233. Edward decide inicialmente no unirse a la rebelión (Scott, Waverley, II, v, p.149), pero la caída en desgracia de su padre le induce a abandonar el ejército y el efecto combinado de las cartas de su coronel ordenándole el retorno al regimiento, que nunca llega a recibir, con las intrigas de Donald Bean convenciendo a sus hombres en su nombre para que deserten, lo convierten en traidor y conducen a su detención. Entonces lamenta no haberse unido a la causa jacobita, aunque, cuando se ve libre para hacerlo, de nuevo duda de qué curso tomar, para finalmente abrazarla de forma inesperada, como resultado tanto de la injusticia con que ha sido tratado como del halo romántico que rodea al príncipe Charles y los términos caballerescos en los que este realiza su apelación a Edward en un encuentro privado entre ambos. Se trata de una maniobra perfectamente orquestada por Fergus MacIvor, que ha movido los hilos y utilizado todos sus recursos (incluida su hermana) desde el principio para conseguir una alianza de gran valor político, ya que Edward pertenece a una eminente familia inglesa de pasado jacobita que puede servir de ejemplo para que otros nobles ingleses se unan a la causa.

40 Scott, Waverley, II, xvi, p.198.

41 El carácter quijotesco de las heroínas de Radcliffe ha sido detectado por Scott Paul Gordon en su magnífico estudio del quijotismo femenino dieciochesco, The Practice of Quixotism: Postmodern Theory and Eighteenth-Century Women's Writing. New York: Palgrave Macmillan, 2006. 
uno nativo y otro foráneo, que ya habían feminizado al héroe novelesco y que además poseen resonancias quijotescas. El primero es el protagonista de The Man of Feeling (1771) de Henry Mackenzie (escocés como Scott y al que este no solo conoció y admiró, sino que significativamente le dedicó la novela que nos ocupa), un personaje cuyo heroísmo espiritual o interior más que físico y cuya alienación del entorno como fruto de su idealismo, inocencia y sensibilidad extremas colocan en la genealogía de Waverley ${ }^{42}$. El otro es el héroe de Die Leiden des jungen Werther (1774) de Johann Wolfgang von Goethe, un autor al que Scott conocía bien, leyó en lengua original e incluso tradujo (tres poemas y la obra de teatro Götz von Berlichinger, que publicó en 1799), y con cuyo Werther Waverley tiene numerosas afinidades: sujetos ambos de un temperamento literario y sońador, dueños de una sensibilidad artística y refinada, y víctimas de un amor contrariado pero sobre todo de su ensimismamiento, introversión y enajenación de la realidad, que finalmente los sitúa al margen de ella como outsiders ${ }^{43}$. Sin citar tales precedentes, la novela llama la atención sobre estas afinidades a través de los comentarios que realizan otros personajes sobre Edward, en los que se incide en la interioridad alienada y ajena al mundo histórico que está en la raíz de la pasividad de Edward: el Barón y Fergus comentan su carácter abstraído, ausente y sońador ${ }^{44}$, en el que también insiste Flora, quien además detecta la discrepancia entre sus sueños heroicos y sus inclinaciones contemplativas, estéticas y, en última instancia, domésticas ${ }^{45}$.

42 Duncan detecta esta genealogía tanto en su libro - "he stands closer to the type of the man of feeling, whose sensibility is the register of a profound apartness" (Modern Romance..., p. 97, y también en p. 64) - como en su introducción a la novela: "... his forebears include eighteenth-century types of extreme sensibility, the 'man of feeling' and the 'female Quixote,' filtered through the beleaguered heroine of Ann Radcliffe's Gothic romances, whose refined imagination supports her amid wild mountain perils" (Introduction, Waverley, p. xix).

43 De las relaciones entre ambos autores se ocupó G. H. Needler en Goethe and Scott. Toronto: Oxford University Press, 1950, donde reduce las relaciones entre Waverley y Werther a las de la trama amorosa: "The manner in which Scott describes the emotionally intense relation between Waverley and Flora shows, I think, that he had in mind the relation of Werther and Lotte as pictured by Goethe in The Sorrows of Werther" (p. 41). El sustrato quijotesco del personaje alemán ha sido investigado por Alfredo Moro en "Afinidades perdidas: Don Quijote, Die Leiden des jungen Werther (1774) y la tradición cervantina alemana”, en Boletín de la Biblioteca de Menéndez Pelayo, vol. 92 (2016), pp. 367-386.

44 Scott, Waverley, II, xx, p. 224.

45 Scott, Waverley, III, v, pp. 264-66. "The real disposition of Waverley, on the other hand, notwithstanding his dreams of tented fields and military honour, seemed exclusively domestic" (Scott, Waverley, p. 264), afirma Flora, constatando el desinterés de Edward por lo que ocurre a su alrededor, por la contienda política de ambiciones que tiene lugar en el breve periodo en que la corte jacobita se instala en Edimburgo y apostillando a la ardorosa defensa de Rose: "... if he were the hero you suppose him, he would interest himself in these matters..." (Scott, Waverley, III, v, p. 265). A continuación, Flora narra la anécdota de cómo en mitad de uno de los episodios de esa contienda, al elevar la voz uno de los contendientes, "Waverley lifted his head as if he had just awaked from a 
El burlón retrato que de Waverley traza Flora es una muy acertada caracterización tras cuyo carácter profético - pues anticipa el final de la novela- puede discernirse la voz autoral: Waverley no es un hombre de acción, sino de reflexión, introvertido como un poeta y no extrovertido como un héroe, más cómodo en la esfera femenina de domesticidad y sensibilidad que en la masculina de guerra y política. $\mathrm{O}$, en otras palabras, es un hombre de letras más que de armas, su imaginación romántica aspira a la aventura caballeresca pero lo predispone a la intelectual o estética. La novela explora este conflicto entre aspiración heroica y temperamento contemplativo del que surge un segundo eje de su quijotismo: junto a la distorsión epistemológica de una imaginación romántica saturada de literatura, la inadecuación heroica del personaje que no está a la altura de sus propios sueños. Para demostrarlo, y he ahí lo novedoso del planteamiento de Scott, mientras que en la tradición cervantina el quijote habitualmente tiene que inventarse una trama romántica irreal en cuyo centro se sitúa para intentar cumplir sus aspiraciones, Scott ofrece a su protagonista la oportunidad de hacerlo situándolo en el centro de una trama que cumple todos los requisitos caballerescos y que es bien real, de hecho históricamente real. El Quijote es la historia de un viejo hidalgo castellano metido por su voluntad a héroe caballeresco, Waverley la de un Werther inglés metido sin querer en un relato de caballerías. En ambos casos, el protagonista no es el héroe que cree ser y se produce una similar crisis del modelo heroico, un mismo divorcio entre acción y creencia en cuyo maridaje se sustenta el heroísmo tradicional: la acción no está a la altura de la creencia.

Ello es notorio, una vez más, desde los primeros capítulos de la novela. El comportamiento de Edward en el regimiento lo aleja ya del héroe que esperaba ser, pues él mismo reconoce que su "wavering and unsettled habit of mind" 46 , del que responsabiliza no solo a su temperamento abstraído sino también a sus erráticas lecturas, le impiden la concentración necesaria para brillar en los ejercicios y destrezas militares, como si los libros hubieran inhibido su capacidad de acción. El episodio del duelo, como hemos visto, lo coloca en una antiheroica posición

dream" (Scott, Waverley, p. 265) y preguntó qué pasaba, provocando la hilaridad de los presentes y su recriminación por no estar plenamente comprometido con la causa y por no asumir el papel y el lugar que le correspondía por sus cualidades. "Yes, he can admire the moon, and quote a stanza from Tasso" (Scott, Waverley, p. 265), repone Flora a la apología de Rose, y, aun concediendo que demostró valor en la batalla, concluye: "But high and perilous enterprize is not Waverley's forte. He would never have been his celebrated ancestor Sir Nigel, but only Sir Nigel's eulogist and poet. I will tell you where he will be at home, my dear, and in his place, -in the quiet circle of domestic happiness, lettered indolence, and elegant enjoyment of Waverley-Honour" (Scott, Waverley, pp. 265-66). La descripción que sigue de un futuro Waverley decorando su biblioteca o rediseñando sus propiedades según el gusto gótico, coleccionando volúmenes para la misma o escribiendo y recitando versos a su mujer, dibuja la figura del diletante romántico que fue el propio Scott.

46 Scott, Waverley, I, vii, p. 34 (énfasis añadido). 
que él mismo percibe ${ }^{47}$, sobre todo siendo un militar, un magnífico ejemplo no de cobardía sino de esa combinación de ceguera e inhibición que lo caracteriza. Y lo mismo puede decirse del accidente de caza, que lo desplaza a segundo plano mientras se tejen los hilos de la rebelión y lo sitúa así en los márgenes no de la historia pero sí de la Historia. Es sintomática también de esa resistencia a ocupar el centro de la acción su decisión, cuando todo lo empuja a abrazar la causa jacobita, de acudir a Edimburgo para defenderse del falso cargo de deserción mediante la ley, es decir, a través de las letras en vez de las armas, dando así la espalda a una cruzada caballeresca comparable a las de los héroes sobre los que tanto ha leído u oído contar, como de nuevo reconoce él mismo: "I had then been free and in arms, fighting, like my forefathers, for love, for royalty, and for fame" 48 . Cuando, finalmente, se une a esta empresa militar, su comportamiento en la batalla no puede en absoluto calificarse de cobarde, pero sí de anómalo de acuerdo a los patrones heroicos. La víspera de la batalla de Prestonpans se queda dormido y tiene que incorporarse apresuradamente al ejército rebelde que, formado y ya en marcha, está abandonando Edimburgo; y, durante la batalla, nunca lo vemos combatiendo al enemigo sino esforzándose por salvar la vida de oficiales ingleses: acude en auxilio de uno que se defiende en solitario (el coronel Talbot) y consigue que se rinda, pero no consigue salvar de la muerte a su antiguo coronel. Todos alaban el ardor guerrero de Waverley por la forma en que se adelanta a sus compańeros en el ataque, pero el lector, sabedor de que lo hace por salvar a Talbot de una muerte segura, no puede evitar considerarlo un malentendido.

Es evidente que el protagonista está lejos de ser el héroe romántico que aspiraba a ser, tal y como Flora, la heroína auténticamente romántica de la novela, detecta y refrenda con el rechazo a sus avances amorosos, y como confirma la eventual aceptación de tales avances por la versión doméstica de la heroína que es Rose. Además, Flora no está sola en la novela como expresión del modelo romántico-caballeresco al que aspira el protagonista y que sirve para poner de manifiesto su inadecuación heroica: por un lado, está Fergus, que es el verdadero hombre de acción, si bien con un lado oscuro que neutraliza su carácter modélico; por otro, el capitán Wogan, que posee tal carácter porque es una figura del pasado, un oficial inglés que desertó de las fuerzas parlamentarias de Cromwell para morir luchando por Carlos II. Es muy significativo que Flora, a decir de su hermano, esté enamorada de su memoria y haya escrito un poema sobre él ${ }^{49}$, que Fergus envía en una carta a Edward precisamente cuando este decide partir a Edimburgo, sin duda para proponérselo como ejemplo y ganarlo para la causa: ese es el héroe que debe ser -y el protagonista cree poder ser- si quiere conquistar 
a Flora. Para el lector implícito de la novela, sin embargo, el poema funciona de manera opuesta a como lo hace para el lector dramatizado que es Edward: como un recordatorio de que no lo es. Paradójicamente, la carta de Fergus acaba sirviendo para hacer pública esa falsa visión heroica de Waverley, pues está en su poder cuando es detenido y se convierte en una evidencia contra él: en la versión que el Mayor Melville reconstruye de los hechos, nuestro protagonista es "the second edition of Cavaliero Wogan" y sus acciones "the very counterplot of ... [Wogan's] plot" ${ }^{\text {" }}$. Pero tanto la historia de Wogan como el relato de Melville son espejos invertidos del protagonista que llaman la atención sobre su inadecuación heroica.

La naturaleza quijotesca de tal inadecuación, sin embargo, adopta en Waverley un nuevo giro que la redefine respecto de su original cervantino. Edward, a diferencia de Don Quijote y al igual que las mujeres quijote en que se inspira Scott, posee todos los requisitos heroicos: juventud, apostura, vigor, nobleza, valor. Por ello, su inadecuación heroica no procede de unas características físicas o genéricas hostiles al universo heroico, como era el caso de Don Quijote, sino de ciertas cualidades internas que son expresión de un contexto epocal, tanto las sociales y civiles sobre las que ha incidido Welsh al estudiar al héroe de las Waverley novels ${ }^{51}$, como las literarias o estéticas en las que hemos incidido más arriba. Y de ello se derivan dos diferencias importantes. En primer lugar, en lo concerniente a estas últimas, es interesante constatar cómo podemos reformular el sagaz diagnóstico de Flora sobre Edward diciendo que la nueva sensibilidad romántica -de Romanticismo- incapacita a Waverley para desempeñar su papel romántico -de romance-, creando así un interesante - por inesperado- conflicto entre Romanticismo y romance (o entre lector Romántico y héroe romántico), que es responsable en gran medida de su inadecuación heroica. Edward puede considerarse el primer quijote Romántico británico en cuanto que integra en su quijotismo aspectos del movimiento literario que se disemina por toda Europa a principios del siglo XIX (la primacía de la imaginación y el sueño sobre la realidad empírica, la estetización y sublimación de la realidad a partir de modelos literarios, la introversión y la alienación), si bien los quijotes sentimentales que, como hemos visto, son sus precedentes, ya habían hecho algo semejante con el Prerromanticismo y Jane Austen había creado una versión femenina publicada poco antes que Waverley. En efecto, en la quijotesca Marianne de Sense and Sensibility (1811), Austen incorpora el Romanticismo además del romance en la construcción de una imaginación romántica femenina y explora el conflicto entre la misma y la realidad. Scott, sin embargo, no utiliza el quijotismo para denunciar la inadecuación epistemológica 
a la realidad de los modelos literarios que la inspiran, como hacía Austen, sino la de la figura quijotesca a esos modelos ${ }^{52}$.

En segundo lugar, y como consecuencia de la raíz interna de tal inadecuación, el antiheroísmo de Waverley es menos obvio o aparente que el del hidalgo, de modo que aquel es -o al menos parece- más héroe que antihéroe, aunque lo sea de forma anómala, inadecuada, fallida. Por ello, y para distinguir tal inadecuación de la de Don Quijote, podemos decir que este es un antihéroe heroico (en su creencia), mientras que Waverley es un héroe antiheroico (en su acción), es decir, quijotesco. El quijotismo matiza o cuestiona el concepto tradicional del héroe para producir un nuevo tipo de heroísmo no heroico, bien dotando al antihéroe de una cierta estatura heroica (el hidalgo resulta ser un héroe), bien rebajando o cuestionando la del héroe (Edward resulta no serlo). Esta segunda posibilidad de un héroe quijotesco había sido ya alumbrada por Tobias Smollett, que creó la primera figuración quijotesca masculina de carácter heroico en su Launcelot Greaves (1760-61), pero ahora se trata de un nuevo tipo de héroe quijotesco. El de Smollett era, a diferencia del de Scott, un héroe plenamente heroico en sus cualidades y en sus logros, en su creencia y en su acción, quijote solo en cuanto que víctima de una enajenación transitoria de raíz amorosa que lo lanzaba a una cruzada caballeresca exitosa pero alienante por su anacronismo e individualismo en un entorno antirromántico y degradado, y es en este conflicto donde radicaba su inadecuación quijotesca. En ambos casos, la inadecuación convierte al heroísmo en quijotesco, pero sus orígenes cambian: Cervantes los había localizado tanto en el entorno como en el héroe; Smollett lo hace en el primero, Scott en el segundo. Frente al héroe indeseado que es Launcelot, Waverley es el deseo de ser héroe; aquel es un héroe alienado, este es un héroe fallido. A caballo entre los siglos XVIII y XIX, quedan así configurados los dos prototipos de héroe quijotesco que convierten a Don Quijote en el paradigma del heroísmo moderno por oposición al tradicional.

\section{Aprendizaje y Desilusión}

Como acabamos de ver, si el quijotismo de Edward Waverley se define en el primer volumen de la obra por una imaginación romántica que colora y literaturiza la realidad, a medida que avanza la novela se dota de una segunda dimensión especialmente notoria en su segundo volumen, la inadecuación heroica, que es en el fondo una extensión de la primera, pues no es sino la discrepancia entre el

52 Sobre la relación de esta y algunas otras heroínas de Austen y la figura del quijote femenino véase Pedro Javier Pardo, "La heroína quijotesca en la novela inglesa del siglo XIX: Austen, Eliot y otros novelistas", en Diego Martínez Torrón y Bernhard Dietz Guerrero (eds.): Cervantes y el mundo anglosajón. Madrid: Sial, 2005, pp. 356-75; y la amplificación y desarrollo de la tesis ahí esgrimida que realiza Miriam Borham en Quijotes con enaguas. Encrucijada de géneros en el siglo XVIII británico. Valencia: JPM, 2015. 
héroe romántico que Edward imagina o aspira a ser y lo que finalmente es. De esta manera, ambas dimensiones convergen en la percepción inadecuada que el protagonista tiene de sí, lo que permite a Scott dar todavía otra vuelta de tuerca a su refiguración del personaje quijotesco. En el tercer volumen se va a narrar la corrección de tal percepción a través de la progresiva toma de conciencia por parte del sujeto quijotesco de su inadecuación tanto epistemológica como heroica, para hacerlo así madurar y acabar asumiendo su verdadera naturaleza y lugar en el mundo. En función de este proceso y su desenlace, la novela puede leerse como la historia de la superación del quijotismo inicial del protagonista a través de un proceso de maduración que le permite finalmente acceder a su auténtica identidad o el tipo de vida para la que está cualificado y, en este sentido, puede considerarse un bildungsroman.

Sin entrar en el debate de qué define o constituye auténticamente este género novelesco, vamos a utilizar el término y su traducción como novela de formación para designar el relato de aprendizaje de un joven, entendiendo aprendizaje en cualquiera de sus sentidos, tanto experiencial como educacional, intelectual y sentimental, de sí y del mundo; como fruto de una voluntad deliberada de formarse o cultivarse y de un ejercicio consciente de introspección por su parte; en el curso del cual se produce su desarrollo y transformación concebida como tránsito no solo físico entre diferentes espacios y aventuras, figuras y amores, sino también espiritual entre inocencia y experiencia, aspiración individual y compromiso social, alienación e integración ${ }^{53}$. Scott utiliza el quijotismo para caracterizar a

$53 \mathrm{El}$ relato de iniciación que podemos encontrar en romances caballerescos y novelas picarescas implica también un aprendizaje a través de la experiencia y un conflicto con la sociedad, pero raramente entraña esa voluntad formativa y capacidad reflexiva, esa dimensión subjetiva e intelectual; y el desarrollo o transformación de sus protagonistas se reduce a la emergencia final de una esencia o identidad fijada de antemano, por el nacimiento o el linaje, bien sea romántica o antirromántica, que les permite su integración final en el mundo al que pertenecen, aunque puede ser de carácter positivo o negativo. En el romance la iniciación conduce a la recuperación de la identidad perdida o a la celebración de la misma en el cénit de un mundo idílico; en la picaresca se concibe como aprendizaje negativo del engaño y la delincuencia que conduce a una falsa integración por lo que entraña de marginación y duplicidad, aunque en la variante francesa representada por Sorel o Lesage (y en sus imitadores ingleses como Fielding y Smollett) adquiere rasgos románticos. Estos textos podrían ubicarse en una zona limítrofe del bildungsroman, la novela de desarrollo (Entwicklungsroman), en la que falta la formación consciente de la personalidad por parte del protagonista, su voluntad de cultivarse y formarse a través de la experiencia; y también hay que distinguir el género de otra forma narrativa de juventud y aprendizaje, la novela de educación (Erziehungsroman), más preocupada por la pedagogía o un aprendizaje reglado. Además, puede distinguirse una utilización estricta del término bildungsroman (la novela de formación) de una amplia (el relato de aprendizaje), en virtud de si la dimensión formativa tiene un carácter estructurante y da forma a la novela o es solo un tema de la misma, como parece ser el caso de Waverley. Sobre el bildungsroman pueden consultarse los estudios clásicos de Franco Moretti, The Way of the World: The Bildungsroman in European Culture. London: Verso, 1978, para el contexto europeo; Martin Swalles, The German Bildungsroman from Wieland to Hesse, Princeton: Princeton University Press, 1978, para la literatura alemana; y Jerome 
ese joven -a través de la lectura, la imaginación romántica y la creencia heroica-, dotando así a tal quijotismo de una nueva dimensión formativa como ilusión romántica juvenil que se cura con la madurez, es decir, a resultas de un proceso de desilusión fruto del aprendizaje, algo que será muy influyente en la concepción decimonónica del mismo. La presencia de la literatura dando forma a la imaginación romántica y a las expectativas heroicas del joven protagonista a través de un deseo de imitación, crea un nexo evidente entre novela de formación y experiencia quijotesca, subrayado en este caso por el carácter caballeresco de tal experiencia, dando lugar así a un tipo de bildungsroman que podemos denominar quijotesco por el quijotismo con el que se caracteriza inicialmente a su protagonista y por la forma en que el proceso de aprendizaje y maduración característico de la novela de formación se identifica con la curación del mismo. Ello implica que tal curación se produce de forma progresiva o gradual y no repentina o súbita, como ocurría en el caso del hidalgo o incluso de los quijotes femeninos, en los que el quijotismo tiene también esa dimensión formativa y se formula por primera vez la ecuación entre curación o abandono del quijotismo y desarrollo o maduración ${ }^{54}$.

Así se hace evidente en Waverley por la manera en que tal proceso está jalonado por una serie de hitos que lo van delineando como aprendizaje progresivo y gradual desilusión: primero la detención y la acusación del mayor Melville y el diálogo con Mr Morton, que le ofrecen una perspectiva de sí y de sus acciones radicalmente diferente ${ }^{55}$; luego el encuentro con el sargento Houghton, que le revela las maquinaciones de Donald Bean a las que ha estado ajeno y también su propia indolencia e indecisión ${ }^{56}$; $y$, finalmente, la batalla de Prestonpans ${ }^{57}$, durante la cual, al verse obligado a combatir a sus antiguos oficiales y compañeros, se siente alienado de la causa que ha abrazado, un auténtico punto de inflexión en el que despierta de su sueño romántico y comienza el retorno a sus raíces inglesas,

Hamilton Buckley, The Season of Youth: The Bildungsroman from Dickens to Golding. Cambridge: Harvard University Press, 1974, para la literatura inglesa.

$54 \mathrm{La}$ enfermedad y las fiebres que acompañan la curación del quijote femenino y dan verosimilitud a su carácter súbito, instituidas por Lennox, aparecen todavía en Austen. Por supuesto, ello no es incompatible con la mella que la experiencia previa (y las enseńanzas de figuras patriarcales: padre, prometido, clérigo) ha hecho en las ilusiones quijotescas y que prepara el terreno para la curación. Además, esta desemboca en boda, es decir, en la asunción del papel y el lugar en el mundo asignado por la sociedad patriarcal y contra el que la heroína se había rebelado en su desvario quijotesco de forma efímera. Por ello, se las califica de novels of female development en los estudios sobre esta tradición dieciochesca que culmina en Burney y Austen (donde el proceso de maduración se desarrolla de forma más clara) escritos por Susan Fraiman, Unbecoming Women: British Writers and the Novel of Development. New York: Columbia University Press, 1993, y Lorna Ellis, Appearing to Diminish: Female Development and the British Bildungsroman, 1750-1850. London: Associated Universities Press, 1999.

55 Scott, Waverley, II, viii, pp. 168-69.

56 Scott, Waverley, II, xxii, p. 233.

57 Scott, Waverley, II, xxiii, p. 236. 
como ha explicado $\operatorname{Kerr}^{58}$. En efecto, a partir de ese momento, Waverley empieza a percibir la realidad escondida tras su romántica percepción de la misma y a distanciarse de la empresa caballeresca jacobita como resultado de una serie de factores: primero, las intrigas políticas de la corte en las que Fergus toma parte activa $^{59}$, pero en las que Edward no tiene el más mínimo interés, lo que da lugar a fricciones entre ellos que modifican la visión que de su amigo había tenido hasta entonces y acabarán conduciendo a la ruptura ${ }^{60}$; luego, el atentado contra él de Callum Beg y la lectura de las cartas que revelan por completo las intrigas de Donald Bean ${ }^{61}$; finalmente, las conversaciones con Talbot, una figura modélica investida de una cierta autoridad paternal, que le transmite una visión extremadamente crítica de sus amigos escoceses, varones y hembras, y en la que se combina sentido común y prejuicio inglés ${ }^{62}$.

El desengaño amoroso parece acabar de abrirle los ojos, pues la resistencia de Flora y el ejemplo de Wogan le hacen comprender que no es el tipo de hombre que ella amaría ${ }^{63}$, que no está a la altura de sus sueños románticos ni en el terreno militar ni el amoroso, lo que le hace decantarse por Rose ${ }^{64}$. En esta conclusión de la trama amorosa de la novela, que es paradójica porque, aun siendo convencionalmente feliz, no deja de ser un fracaso, está prefigurada su renuncia a tales sueños, que acabará de producirse como consecuencia del fracaso en el otro terreno, el militar, con la desolación que la derrota de la rebelión jacobita trae a sus amigos escoceses y a sí mismo. En la soledad del escondite donde bajo una falsa identidad se refugia de las represalias que su participación en la rebelión puede traerle, culmina el proceso de desilusión:

.... and it was in many a winter walk by the shores of Ulswater, that he acquired a more complete mastery of a spirit tamed by adversity, than his former experience had given him; and that he felt himself entitled to say firmly, though perhaps with a sigh, that the

58 "Waverley now sees the dream for what it is, realizing the unreality of his life up to this instant. This moment of self-recognition will eventually lead him out of the land of 'military and romantic adventure and into the 'reality' of the historical present. It is a turning point in Waverley's gradual movement back towards his native society, to the mid-eighteenth-century England from which he has been a fugitive. Hereafter, Waverley's development is described as the process of awakening from a dream. The changes he undergoes are presented as an emergence from the fantasy-life which he had lived in his Northern haven and his entry into a world which has 'history' rather than legend and romance..." (Fiction Against History, p. 35, énfasis añadido).

59 Scott, Waverley, III, iii, p. 253.

60 Scott, Waverley, III, x, p. 284.

61 Scott, Waverley, III, iv, pp. 257-60.

62 Scott, Waverley, III, v, pp. 262-63.

63 Scott, Waverley, III, vii, p. 270.

64 Scott, Waverley, p. 271. 
romance of his life was ended, and that its real history had now commenced. He was soon called upon to justify his pretensions to reason and philosophy. ${ }^{65}$

Este famoso pasaje del volumen tercero presenta el proceso de aprendizaje y maduración propio de la novela de formación como un abandono del romance para abrazar la Historia, es decir, la realidad, vinculándolo así de forma inequívoca con el final del quijotismo romántico del personaje. Podemos caracterizar este momento como una anagnórisis quijotesca, pues no es sino una toma de conciencia de su propio quijotismo que le permite superarlo, asumir la realidad de su vida y reconocer su verdadera naturaleza. Si la anagnórisis romántica, es decir, la que suele ser el clímax del romance, consiste en la revelación y recuperación tanto personal como social de la identidad perdida del héroe o la heroína, esta de la novela de Scott es su doble antirromántico, en cuando que entraña renunciar a la identidad romántica soñada para asumir una histórica o incluso prosaica, y es el clímax del proceso de aprendizaje y desilusión del héroe.

Sin embargo, no conviene exagerar esta dimensión antirromántica de la novela, ya que la anagnórisis está teñida de una cierta nostalgia y añoranza del romance perdido que es un reflejo de la que revela Scott en la obra en su conjunto y, además, abre paso a un desenlace que tiene algo de romántico, como ha argumentado Duncan: el héroe cuyos descarríos a punto están de acabar en tragedia, no solo salva la vida, su fortuna y sus propiedades, sino también las del Barón de Bradwardine, para casarse con su hija Rose y terminar la novela instalado en un idilio doméstico. Más que de anti-romance deberíamos hablar de un tipo diferente de romance, doméstico en vez de heroico, sentimental y no caballeresco, como deja claro el propio Edward al declarar su hastío de la guerra ${ }^{66}$ y su interés exclusivo en $\operatorname{Rose}^{67}$. En este respecto, estamos ante una forma híbrida de romance y realidad no tan diferente de la de Fielding (o incluso Austen), cuya alargada sombra se deja sentir en este y en otros aspectos de la novela. Pero este feliz desenlace va acompañado de un cierto sentimiento elegíaco y hasta trágico que lo diferencia de Tom Jones. Así lo revelan las reflexiones del protagonista al volver a Tully-Veolan, que además dejan claro no solo el proceso de aprendizaje y maduración con el que ha superado su quijotismo juvenil, sino la conciencia del mismo por parte del personaje: "Now how changed, how saddened, yet how elevated was his character, within the course of a few months! ... 'A sadder and a wiser man,' he felt, in internal confidence and mental dignity, a compensation for the gay dreams which 
in his case experience had so rapidly dissolved" ${ }^{68}$. La cita de Coleridge llama la atención sobre la tristeza que acompaña a la madurez que da la experiencia, algo que en este caso se justifica plenamente, además de por el trágico destino de los McIvor y el fin de una forma de vida que ellos representan, porque tal experiencia implica el conocimiento no solo del mundo que frustra nuestras aspiraciones románticas, sino, sobre todo, de nosotros mismos, que rara vez estamos a la altura de nuestros sueños.

Sea como fuere, Scott ha dado forma quijotesca a tales sueños y, al hacerlo, ha asociado el quijotismo con las fantasías juveniles y lo ha convertido en un estadio en la formación de un personaje que se supera con el aprendizaje y la desilusión, y con ello en un factor en la fórmula narrativa que explora tal aprendizaje. Waverley, por tanto, no es solo la culminación de la refiguración romántica del quijote o de su vinculación a juventud e inexperiencia que se inicia en la novela británica del siglo XVIII, sino que también inaugura una tradición narrativa en lengua inglesa que lo incorpora a un proceso de crecimiento y maduración, dotándolo así de una nueva dimensión y función, la formativa, que por esos mismos años explora también en el terreno femenino Jane Austen. Dicha tradición, sin embargo, tiene orígenes foráneos, concretamente germánicos, como no podía ser menos en estos inicios del siglo XIX, cuando Alemania genera nuevas ideas literarias que se diseminan por toda Europa. Naturalmente, Scott pudo reconocer en el Wilhelm Meister (1795-96) de Goethe el prototipo de bildungsroman ampliamente reconocido como fuente y agente responsable del auge de este género en la literatura europea del siglo XIX y pudo encontrar en él aspectos que reproduciría en su joven protagonista $^{69}$. Pero lo que diferencia a Wilhelm Meister de Waverley es precisamente la forma quijotesca que el relato de aprendizaje adopta en Scott por el papel que en tal proceso de aprendizaje juega la imaginación romántica fruto de la condición de lector del protagonista; por los modelos literarios caballerescos y las pretensiones heroicas que genera en él; y por la caracterización de este proceso como el correctivo a tales expectativas heroicas. Este quijotismo formativo ausente en Goethe, Scott pudo encontrarlo en las obras de Cristoph Martin Wieland, para muchos el creador de la novela alemana a partir del ejemplo tanto de Cervantes como de su más famoso imitador inglés, Henry Fielding, como ha demostrado Moro en un reciente libro sobre el tema, donde además recoge la influencia que tal concepción de la novela -el método cervantino- ejerció en Scott ${ }^{70}$. Wieland no solo es autor del que puede considerarse el primer bildungsroman, Agathon

68 Scott, Waverley, III, xvi, p. 315.

69 Véase el estudio de Susan Howe, 'Wilhelm Meister' and his English Kinsmen. New York, AMS Press, 1966, sobre la influencia de Wilhelm Meister en la novela victoriana, que sugiere conexiones posibles con Waverley solo de forma implícita, ya que en él no figura Scott.

70 Alfredo Moro, Transformaciones de la novela cervantina en la novela inglesa y alemana del siglo XVIII. Alcalá de Henares: Universidad de Alcalá, 2016. 
(1766-67), sino que comienza a tantear o acercarse a esta forma narrativa en una novela anterior, Don Sylvio von Rosalva (1764), la primera de su producción, protagonizada por una figura juvenil literal y explícitamente quijotesca situada a medio camino entre el hidalgo manchego y su posterior metamorfosis escocesa.

Entre las novedades que Waverley presenta en relación con esta tradición alemana, hay una en la que merece la pena detenerse porque dota al proceso de formación descrito en la novela de un carácter distintivo que podemos caracterizar como doblemente quijotesco. Llama la atención, en efecto, que tal proceso culmina antes del final de la obra, con ese reconocimiento del fin del romance of his life y el retorno a Tully-Veolan. Ello explica que en las páginas finales Edward sea desplazado del centro de la acción por el Barón de Bradwardine (Cosmo Comyne Bradwardine of Bradwardine), quien, con la ayuda de criados leales, sobrevive escondido en los dominios de los que ha sido desposeído, adquiriendo así un inesperado protagonismo que pone en primer término el quijotismo que lo ha caracterizado a lo largo de toda la obra y nos invita a repensar la función del mismo en la novela.

En efecto, el carácter quijotesco del Barón se pone de manifiesto desde los inicios de Waverley y se fundamenta en su erudición libresca: "He was a man of very ancient family and somewhat embarrassed fortune; a scholar, according to the scholarship of Scotchmen, that is, his learning was more diffuse than accurate, and he was rather a reader than a grammarian" ${ }^{\prime 1}$. Pero lo que hace quijotesca esta erudición es la manera en que la utiliza, salpicando su discurso a la menor oportunidad de continuas citas en latín o referencias a los clásicos y a otras oscuras fuentes, tiñendo su vida y opiniones de un marcado carácter libresco, anacrónico y retórico que hacen pensar no solo en el hidalgo sino en alguno de sus descendientes. En este sentido, aunque su predilección por los clásicos y su necesidad de llevarlos con él recuerda al Adams de Fielding viajando siempre con su copia de Esquilo (tras ser hecho prisionero en la campaña jacobita de 1715 consigue escaparse, pero es apresado de nuevo porque vuelve para buscar su Tito Livio), su caracterización es claramente deudora de los pedantes quijotescos del XVIII. Así lo confirman los episodios en los que observamos el carácter tanto trivial como central que convierte esa erudición en pedantería, que es la marca de fábrica de Cornelius en las Memoirs of Martinus Scriblerus (1741), la obra colaborativa de Swift, Pope y demás miembros del Scriblerus Club, o del Walter Shandy de Sterne, por citar los dos ejemplos más conocidos del erudito dieciochesco del que me he ocupado en otro lugar. ${ }^{72}$ Sin embargo, a diferencia de estos modelos, la

71 Scott, Waverley, I, vi, p. 28.

72 Pedro Javier Pardo, "Satire on Learning and the Type of the Pedant in Eighteenth-Century Literature”, en BELLS, vol. 13 (2004), en línea: http://www.publicacions.ub.es/revistes/bells13. La conexión con este tipo queda ya clara en la primera aparición el Barón citando en latín una frase que afirma su anacrónica prerrogativa de arrestar, juzgar y ejecutar a sus inquilinos y vasallos (Scott, 
erudición latina del Barón aparece felizmente combinada con su carácter de militar y adquiere así tintes caballerescos, como ocurría con otro excéntrico escocés cuya estampa era un calco de la de Don Quijote, el capitán Lismahago creado por Smollett en Humprhy Clinker (1771). Esas dos facetas representan no solo la conjunción de armas y letras por la que abogaba el hidalgo, sino también de las dimensiones admirable y ridícula de este, como recogen las palabras de Fergus: "He has seen much [military] service ... and one is sometimes astonished to find how much nonsense and reason are mingled in his composition"73. Y es esta dimensión cómica en un quijotismo de índole intelectual, junto a la literalidad que viene dada por una edad, ocupación y aspecto similares al hidalgo -su figura magra y excéntrico atuendo se destaca en su primera aparición ${ }^{74}-$ lo que lo diferencia del desplazamiento juvenil e imaginativo que caracteriza al de Waverley, una diferencia reflejada en las fuentes literarias de que se nutren uno y otro $^{75}$. Si el quijotismo de Waverley, asociado a imaginación e inexperiencia, es serio y romántico, el de Bradwardine, concebido como manía y excentricidad, es cómico y antirromántico.

Pero, más allá de que representen diferentes tipos de quijotismo, lo realmente significativo es que la relación entre ambos personajes que describe la novela, de tintes paterno-filiales, tiene la virtud de vincularlos en una genealogía no solo biológica -quijote de juventud y de senectud- sino también literaria -el quijote antiheroico dieciochesco y el nuevo héroe quijotesco decimonónico- ${ }^{76}$. Un em-

Waverley, I, x, pp. 44-45). No tiene desperdicio su disquisición erudito-militar a propósito de la supuesta deserción de Edward e ingreso en las filas del príncipe Estuardo (Scott, Waverley, II, xviii, pp. 212-13), trufada de términos latinos y donde la autoridad del ilustre Cicerón se combina con la de un oscuro Sánchez cuya obra citada, De Jure-jurando, nos informa el anotador, no existe o corresponde a otro autor. Y su quijotesco abuso de erudición llega al culmen con su consulta a Fergus y Edward sobre si y cómo debe cumplir el acto de homenaje estipulado en sus oscuras fuentes, consistente en quitarle las botas al príncipe, quien, por cierto, no lleva botas (Scott, Waverley, III, i, 245-47). Se trata tanto de una disquisición filológica sobre los términos latinos en que se enuncia la norma feudal, sirviéndose de recónditas y eruditas fuentes (entre las que echa en falta una sobre las cosas de vestir, de re vestiaria), como de un ejercicio de anacrónico formalismo en el seguimiento de las normas que regulaban la relación del señor con sus vasallos y que ya están desfasadas. De manera muy sintomática, Fergus detecta inmediatamente la dimensión ridícula y risible de su comportamiento y se refiere a él como absurd original (Scott, Waverley, p. 247), un apelativo característico de los quijotes dieciochescos, pero no así Edward, lo que apunta a su sustrato quijotesco común de índole caballeresca (Scott, Waverley, p. 255).

73 Scott, Waverley, II, xxiii, p. 237.

74 Scott, Waverley, I, x, p. 44.

75 Scott, Waverley, I, xiii, pp. 61-62.

76 Ambos tipos reaparecerán en las novelas posteriores de Scott: por citar solo los ejemplos más inmediatos, en sus dos siguientes novelas podemos encontrar al joven, de forma más difuminada, en el protagonista de Guy Mannering (1815), y al viejo, con contornos quijotescos aún más claros y en la misma tradición erudita dieciochesca que el Barón, en el Jonathan Oldbuck de The Antiquary (1816). La conexión entre Oldbook y Don Quijote fue apuntada tempranamente por Bell cuando 
parejamiento similar de lo que podríamos denominar veteroquijotismo y novoquijotismo se había ya apuntado levemente en el Launcelot Greaves de Smollett, pero es Scott quien los vincula claramente en esta novela que puede considerarse fundacional por el impacto que tendrá en la novela decimonónica, donde convivirán ambos tipos de quijotismo, como puso de manifiesto Alexander Welsh ${ }^{77}$. En Waverley, además, el vínculo paterno-filial de esta dualidad tiene la virtud de sugerir no solo los orígenes literarios de ese nuevo quijotismo, sino su desarrollo y evolución biológica, o, en otra palabras, el hecho de que el quijotismo juvenil no desaparece sino que se transforma con la edad: tal vez Bradwardine sea el tipo de quijote en que se convertirá Waverley con los años, cuando el idealismo romántico y caballeresco ceda su lugar a uno intelectual y doméstico, cuando la biblioteca no sea ya un espacio en el que ejercitar la imaginación exaltada sino una aguda bibliomanía, cuando la empresa heroica se convierta en la actividad del poeta o el anticuario ${ }^{78}$. Las dos figuras quijotescas de la novela parecen así sugerir que el quijotismo formativo, que moldea románticamente la personalidad y visión de mundo, sueños y expectativas de un joven, deja paso a uno monomaníaco que condiciona como idea fija los hábitos intelectuales y discursivos de una figura ya madura: la exaltación imaginativa se cura con la edad y cede su lugar a una condición cotidiana que acompaña hasta la tumba. Esta visión del quijotismo que podría calificarse de generacional hace el relato de aprendizaje en Waverley aún más - por doblemente- quijotesco: el proceso de maduración característico de este tipo de novela, Scott parece decirnos, no es sino la transición de un tipo de quijotismo a otro.

extrae de la novela de Scott un pasaje en la que se cita al segundo como el modelo de la bibliomanía del primero (71), pasaje que luego Horst citará por extenso (207); pero su quijotismo no reside en tal bibliomanía, sino en la actividad libresca e intelectual asociada a aquella y que lo caracteriza, al igual que a Bradwardine, como pedante quijotesco. Esta dimensión de Oldbook ha sido estudiada por Ina Ferris en "Pedantry and the Question of Enlightenment History: The Figure of the Antiquary in Scott", en European Romantic Review, vol. 13, no 3 (2002), pp. 673-683, donde la descripción que esta autora hace de su producción discursiva en forma de disquisiciones, tratados y publicaciones varias no deja lugar a dudas de su relación con los anticuarios, virtuosos y críticos textuales del siglo XVIII. De la quijotesca bibliomanía de Bradwardine como reflejo de la del propio Scott se ha ocupado Peter Garside en "The Baron's Books: Scott's Waverley as a Bibliomaniacal Romance", en Romanticism, vol. 14, no 3 (2008), pp. 245-258, donde hace un interesante recorrido por su biblioteca mental, pues es muy llamativo que sus fuentes librescas no se localizan en espacio físico alguno, sino en su prodigiosa memoria.

77 Alexander Welsh, Reflections on the Hero as Quixote. Princeton: Princeton University Press, 1981, p. 16

78 Así parece sugerirlo también el sarcástico comentario de Fergus en que asocia las veleidades poéticas de Edward con el anticuarianismo propio del Barón: "Well then, I shall certainly find you exerting your poetic talents in elegies upon a prison, or your antiquarian researches in detecting the Oggam character, or some Punic hieroglyphic upon the keystone of a vault, curiously arched" (Scott, Waverley, II, v, p.150). 


\section{LA NOVELA DEL HÉROE FALLIDO}

Scott pasa a Cervantes por el alambique de sus modelos dieciochescos tanto ingleses como alemanes, especialmente Wieland pero también Goethe, para destilar una fórmula que vamos a reencontrar en muchas novelas decimonónicas no solo inglesas sino también francesas: el joven quijotesco en el que la lectura y el deseo de imitación hace germinar tanto una imaginación romántica como una aspiración heroica y que experimenta un proceso de aprendizaje de los límites tanto de sí mismo como del mundo, en virtud del cual toma conciencia de la inadecuación entre ambos, abandona sus ilusiones quijotescas y se convierte en un adulto pleno. Así lo apuntó Alexander Welsh en el estudio que se adentró por vez primera en el poco transitado camino del quijotismo decimonónico al detectar la raigambre quijotesca de Waverley: "Scott began writing novels by sketching a hero who was in some ways a youthful counterpart of Don Quixote ... From this redefinition of quixotism great numbers of nineteenth-century heroes and heroines are descended"79. Y a esta afirmación sigue un comentario capital para entender el papel de Scott como mediador entre Don Quijote y un nuevo tipo de héroe:

When the cure for quixotism consists simply in growing up, the nineteenth-century novel of disillusionment has been founded. English novels that pursue this plan-Pendennis, David Copperfield, the Dorothea Brooke part of Middlemarch-show that the "romantic" character of the hero is temporary by treating him or her to an experience of conversion or process of maturing. French instances-Le Rouge et le noir, Illusions perdues, L'Éducation sentimentale-tend to show the hero persisting in his illusions and thereby more easily earn for their authors a reputation as realists. The new and subtle contribution of nineteenth-century novels is in the nature of heroes' aspirations, which are not wholly equated with the aspirations of the culture. They need not be chivalric-they may be almost any aspirations at all, from grandly altruistic to pettily selfish. ${ }^{80}$

Sobre esta clase de novela decimonónica evocada por Welsh había ya escrito Georg Lukács, quien la designaba como novela de la desilusión y la definía por el romanticismo desilusionado de sus héroes, esto es, "an over-intensified, over-determined desire for an ideal life as opposed to the real one. A desperate recognition of the fact that the desire is doomed to remain unsatisfied, a utopia based from the start on an uneasy conscience and the certainty of defeat" ${ }^{\prime 1}$. Este

79 Welsh, Hero as Quixote, pp. 149-50.

80 Welsh, Hero as Quixote, pp. 150-51 (énfasis añadido).

81 Georg Lukács, The Theory of the Novel. London: The Merlin Press, 1971 (1920), p. 116. 
autor había detectado también su conexión cervantina en el conflicto entre el yo y el mundo o entre interioridad y realidad, aunque con la salvedad de que el idealismo abstracto que reduce el mundo a una idea del mismo propio del hidalgo es sustituido por el romanticismo de personajes que ven el mundo más amplio y rico de lo que realmente es, y la acción en que se manifiesta aquel es reemplazada por el carácter contemplativo de estos ${ }^{82}$. Y Harry Levin volvía sobre la desilusión en su estudio de la narrativa francesa del siglo XIX para describir su realismo también en clave cervantina. En efecto, tras caracterizar el realismo del Quijote por su carácter antirromántico, es decir, por la negación de las ilusiones inspiradas en el romance caballeresco y representadas por el hidalgo a través de "the literary technique of systematic disillusionment", añade que "it was in nineteenth-century France that the example of Don Quixote proved the most fruitful... It was the original stimulus for Stendhal and Flaubert, as they both admitted..." ${ }^{\prime 3}$. En estos autores y también en Balzac, Levin identifica un tipo de personaje al que califica de imaginist y del que cita también como ejemplos al Waverley de Scott o al Feverel de Meredith, del que nos ocuparemos más abajo ${ }^{84}$.

Para todos estos autores la desilusión del héroe que resulta del conflicto entre sus aspiraciones y la cultura en que habita (Welsh), entre su visión expansiva o ampliada del mundo y el mundo real (Lukács), o entre sus expectativas románticas y la realidad (Levin), parece ser la clave de la herencia quijotesca en la narrativa decimonónica. El énfasis recae así en esa inadecuación entre un yo que forja una idea del mundo y el mundo real, pero es necesario reivindicar también el papel que juega en ese proceso la inadecuación del yo a su idea de sí mismo (que es parte fundamental en esas expectativas, visión o aspiraciones), es decir, el carácter fallido del héroe: la desilusión es en gran medida desilusión de sí. Y es en esta dimensión donde la ejemplaridad de Don Quijote y de su reescritura como héroe

82 A propósito de esta inacción o falta de participación en el mundo de los héroes románticos de la desilusión, Lukács añade algo que completa su relación inversa con Don Quijote: "The romanticism of disillusionment not only followed abstract idealism in time and history, it was also conceptually its heir, the next historic-philosophical step in a priori utopianism. There, the individual, the vehicle of the utopian challenge to reality, was crushed by the brute force of reality; here, defeat is the precondition of subjectivity" (Lukács, The Theory of the Novel, p. 117).

83 Harry Levin, The Gates of Horn: A Study of Five French Realists. New York: Oxford University Press, 1963 , pp. 48 y 46.

84 "...the novel if disillusionment thus becomes the novel of development, a Bildungsroman. Every great novelist since Cervantes has played his own variation on the theme that Balzac epitomized in Illusions perdues. Voltaire's [in Candide] is perhaps the neatest and the most schematic... Meredith's is altogether different, yet Richard Feverel is also suspended between the aprioristic and the actual ... Those who deplored the disillusioned novels about the first World War forgot that it has always been the method of realistic fiction to undermine a series of preconceptions. Romantic presuppositions, like those which Scott attributed to his Waverley, are tested under trying circumstances. The protagonist has been an 'imaginist' like Jane Austen's Emma-or, for that matter, Flaubert's" (Levin, The Gates of Horn..., p. 52-53). 
quijotesco por parte de Scott parece más evidente. El Quijote no es el paradigma novelesco de la desilusión porque el hidalgo recupere finalmente la cordura y abjure de su fe caballeresca, pues ello no es fruto de aprendizaje o proceso alguno, sino algo repentino e inexplicado que permite a Cervantes darle muerte y blindar su novela contra futuros Avellanedas; lo es por el proceso de desengańo narrado en la segunda parte que no tiene como objeto sus ideales sino su capacidad para llevarlos a término y que culmina con su fracaso final. Tal fracaso toma cuerpo ya desde el inicio en el motivo de la Dulcinea encantada, una fuente de impotencia y frustración crecientes para el hidalgo cuyo impacto psicológico se hace visible en el descenso a la cueva de Montesinos. A ello hemos de unir la pérdida de iniciativa en su empresa caballeresca observable a lo largo de toda la segunda parte, especialmente en el palacio de los Duques. Y el colofón lo pone la derrota por el de la Blanca Luna y el retorno a la aldea. Don Quijote no vuelve desilusionado de su mundo caballeresco, sino de sí y de su condición de caballero andante, convertido no en el héroe que creía ser sino en un héroe fallido o desengañado de él mismo como héroe. Esa es la lección que desarrolla Scott al concebir el quijotismo como imaginación romántica juvenil adquirida a través de la lectura e incorporarlo como inadecuación heroica al proceso de aprendizaje y desilusión de Waverley. Y tal lección es la que aprenden de Scott algunos novelistas del siglo XIX cuyos personajes, aun cuando sus sueños o aspiraciones no tengan un contenido explícitamente quijotesco dado por su carácter caballeresco, heroico o romántico, tienen forma quijotesca por sus orígenes literarios, por la distancia imaginativa que los separa de la realidad, especialmente la suya propia, y por su devenir que los aboca al fracaso y la desilusión.

Tal es el caso de Julian Sorel, que protagoniza Le Rouge et le Noir (1830) de Stendhal, cuya inclinación por las letras y los estudios y sobre todo su lectura del Mémorial de Sainte-Hélène, que conoce casi de memoria, confiere a sus sueños el carácter literario e imitativo típico del quijotismo, pues modela su ideal de vida y conducta sobre el de Napoleón que encuentra en ese libro. Estamos ante un nuevo giro al quijotismo bien explicado por René Girard cuando lo caracteriza por su deseo triangular, es decir, por la intervención de un mediador al que se imita cuando se desea lo mismo que él y porque él lo desea, sea este Amadís de Gaula o Napoleón Bonaparte, lo que implica trasladar el énfasis del componente literario al imitativo del quijotismo y plantear la posibilidad de que la imitación pueda tener un modelo histórico en vez de ficticio, aunque esté igualmente codificado en forma literaria o textual ${ }^{85}$. Además, este mediador es ahora más cercano en cuanto

85 René Girard, Mensonge romantique et vérité romanesque. Paris: Bernard Grasset, 1961. "Don Quichotte a renoncé, en faveur d'Amadis, à la prérogative fondamentale de l'individu: il ne choisit plus les objets de son désir, c'est Amadis qui doit choisir pour lui. Le disciple se précipite vers les objets que lui désigne, ou semble lui désigner, le modèle de toute chevalerie. Nous appellerons ce modèle le médiateur du désir. L'existence chevaleresque est l'imitation d'Amadis au sens où l'exis- 
que forma parte del universo del héroe, es interior en vez de exterior al mismo, y esta proximidad desprovee a la imitación tanto de carácter ridículo como romántico. Lo primero porque el modelo de héroe napoleónico imitado por Sorel no proviene del romance sino de la historia, y en ese sentido es plenamente factible y verosímil; lo segundo porque de él toma no tanto su idealismo revolucionario, aunque posee la dosis justa del mismo y la nobleza de espíritu suficiente para dotar a Julien, si no de estatura heroica, al menos sí de una cierta superioridad frente a un entorno corrupto; como un modelo de éxito o una camino de ascenso social, lo que lo acaba rebajando por el ejercicio de disimulo o incluso hipocresía que debe asumir en un entorno hostil y tiñe de arribismo la imitación de su ideal. El modelo sigue siendo ideal porque, como explica Girard, no importa lo material o incluso interesado de la imitación, el deseo triangular transfigura el objeto deseado por el prestigio del mediador y lo envuelve en un halo de ilusión, quimera, sueño, ideal en cuanto que idea. Pero se trata de un ideal impuro, en la acertada descripción de Bardon ${ }^{86}$, por su naturaleza egoísta en vez de altruista, puramente personal y pragmática.

Sorel comparte en este sentido la imaginación exaltada que irradia ilusión allá donde se proyecta y que caracterizaba al héroe quijotesco de Scott, pero ha perdido su carácter no solo caballeresco sino también romántico. Además, sustituye el carácter contemplativo y pasivo de aquel por uno activo y combativo que, sin embargo, tampoco le permite cumplir el destino para el que se creía llamado, pues se descontrola en el terreno amoroso: si bien en primer término sus sucesivas relaciones con Madame de Renal y Mathilde de la Motte le permiten acceder al gran mundo y parecen encumbrarlo, su intento de asesinato de la primera acaba truncando su ascenso y provocan su caída. Si Edward pecaba por defecto y la acción no estaba a la altura de la creencia, Sorel lo hace por exceso y la acción desborda la creencia, pero ambos comparten un similar desconocimiento de sí, como sugiere Bardon cuando compara a este con Don Quijote por su incapacidad de juzgarse, de distanciarse de sí mismo para apreciar lo descabellado de sus preten-

tence du chrétien est l'imitation de Jésus-Christ" (16). Girard precisa las diferencias entre el mediador cervantino y el stendhaliano: "Chez Cervantès, le médiateur trône dans un ciel inaccessible et il transmet à son fidèle un peu de sa sérénité. Chez Stendhal, ce même médiateur est descendu sur terre. Distinguer clairement ces deux types de relations entre médiateur et sujet, c'est reconnaître l'écart spiritual immense qui sépare un Don Quichotte des plus baisement vaniteux parmi les personnages stendhaliens" (21); por tanto, "les oeuvres romanesques se groupent donc en deux catégories fondamentales... Nous parlerons de médiation externe lorsque la distance est suffisante pour que les deux sphères de possibles dont le médiateur et le sujet occupent chacun le centre no soient pas en contact. Nous parlerons de médiation interne lorsque cette même distance est assez réduite pour que les deux sphères pénètrent plus ou moins profondément l'une dans l'autre" (pp. 22-23).

86 Maurice Bardon, "Don Quichotte et le roman réaliste français: Stendhal, Balzac, Flaubert", en Revue de littérature comparée, vol. 16 (1936), pp. 63-81. p. 67. 
siones y $\operatorname{actos}^{87}$. Como Don Quijote, ninguno de los dos llega a ser el sujeto que pensaba que era o a ocupar la identidad que había imaginado, aunque el fracaso es más radical en el caso de Sorel, y no solo por su muerte, sino por su negativa previa al reajuste o el compromiso con la realidad, es decir, por la aparente falta de aprendizaje o maduración.

Welsh ha detectado con acierto este salto de la extroversión a la introversión, de lo colectivo a lo personal o incluso egótico, que se hace evidente en el héroe quijotesco de Stendhal, aun cuando hunda sus raíces en el de Scott: "All these characters, French and English, seem far different from true quixotic heroes unless one accepts as decisive the innovation apparent in Waverley-the substitution of personal longing or ambition for chivalric motives" ${ }^{38}$. Entre los personajes aludidos por Welsh ocupa un lugar de privilegio en lo que a este particular se refiere Lucien de Rubempré, que aparece en la novela de Honoré de Balzac Illusions Perdues (1837-43), o el que para Welsh (p. 155) es su pariente inglés más cercano (también de Sorel), el Pip de Great Expectations (1860-61), cuya aspiración de convertirse en un caballero y pertenecer al gran mundo del que inicialmente está excluido por su orfandad, queda dramatizada, de manera similar a sus precedentes franceses, en un tránsito de provincias a la metrópoli y encarnada en una mujer a la que idealiza. Los ejemplos tanto de Rubempré como de Pip ponen de manifiesto no solo un desplazamiento del quijotismo desde lo caballeresco, heroico o romántico hacia lo simplemente imaginativo, sino también una progresiva difuminación del modelo literario imitado que en Waverley y Sorel ocupan un primer plano. Ello se hace evidente de manera más significativa en L'Éducation sentimentale (1869), la novela de Gustave Flaubert en la que esta tradición francesa del quijotismo impuro vuelve a sus orígenes escoceses para recuperar algo de su perfil más puramente quijotesco.

Tal retorno se anuncia ya cuando el capítulo segundo de la novela explica que su protagonista, Frédéric Moreau, imbuido de sus lecturas medievales, sueña con ser el Walter Scott de Francia para darles forma novelesca. Si la referencia es una pista indudable sobre las intenciones de Flaubert de someter la imaginación literaria de su héroe a la prueba de la historia, en este caso la revolución de 1848, imitando el plan de las novelas de Scott, no puede decirse que lo sea también sobre el mediador que orienta la imitación de su protagonista, que solo aflora unas páginas más adelante en algunas referencias que se dejan caer apresuradamente para ser luego olvidadas: Werther (Goethe), René (Chateaubriand), Lara (Byron) y algún otro personaje menos conocido con los que la conducta de Frédéric guardará interesantes paralelismos. Ello permite situar sus modelos literarios en un Romanticismo casi contemporáneo, lo que, siguiendo a Guirard, caracteriza esta

87 Bardon, “Don Quichotte et le roman réaliste français...", p. 67.

88 Welsh, Hero as Quixote, p. 156. 
mediación como interior y explica la ocultación de la misma por rivalidad que sustituye a la proclamación reverencial propia de la exterior. El Romanticismo literario que está en el trasfondo de su quijotismo aparece confirmado en las lecturas que hace a Louise cuando es niña, o en su evocación del Antony de Dumas y de Werther como fuente de su comportamiento. Estos son los únicos momentos en que se deja traslucir un cierto carácter imitativo en su comportamiento; pero la imitación queda apuntada más que desarrollada, es implícita más que explícita; y parece circunscrita al ámbito amoroso. En efecto, estos modelos puede que tengan algo que ver con la idea de sí mismo como alguien superior y extraordinario, que se materializa primero en su proyecto de convertirse en un gran escritor, al que sucederá luego el de ser pintor. Pero esta aspiración artística acabará siendo desplazada por la ambición política, el mero afán de ascenso social, contaminando así su ideal de la impureza que ya hemos visto en sus precedentes franceses.

Como los héroes de Balzac y Stendhal, los sueños de Moreau tienen más que ver con el éxito personal que con un destino heroico, con un triunfo imaginado más que con la imaginación romántica. Frédéric recorre el mismo itinerario físico que ellos de la provincia a París para triunfar en el mundo, una similitud subrayada por la referencia al Rastignac de la Comédie humaine que hace su aparición también en Illusions perdues y que su amigo Desaluriers le propone como ejemplo del éxito que le espera allí. Pero, a diferencia de tales héroes, Moreau sufre de una apatía o pasividad reminiscente de la de Waverley, una radical ausencia de voluntad que le impide conseguir sus objetivos o ser lo que quería ser y lo convierte en espectador más que actor de su propia vida. Ello es evidente desde que entra a trabajar en un bufete tras su primer retorno de París a la provincia y el narrador describe su desempeño como una decepción pública, lo que paradójicamente le hace concebir la ambición de llegar a ministro; pero no le vemos hacer nada por conseguirlo, ni por llegar a secretario del Consejo de Estado, ambición que fía a las maniobras de otros, o a diputado por su provincia de origen, que se frustra de nuevo porque no es capaz ni de desplazarse allí para proponer su candidatura. Podría pensarse que este desinterés por lo público es debido a la intensidad con la que vive su pasión por Madame Arnoux, su auténtica Dulcinea por el proceso de idealización que la novela describe, como ha apuntado Welsh ${ }^{89}$. En este sentido, es paradigmática la escena en que, mientras estalla el motín que da inicio a la revolución de 1848 en las calles de París, Frédéric está concentrado en la cita minuciosamente preparada con Madame Arnoux y ello lo reduce al papel de espectador desinteresado; pero ella no acude a la cita, por lo que la escena acaba siendo paradigmática de su frustración y falibilidad tanto en el amor como en la política, las dos esferas en que Scott articulaba el heroísmo fallido de Waverley. Como muestra esta cita frustrada (o el duelo frustrado que nos hace recordar el 
uso similar de este motivo por parte de Scott), el quijotismo de Moreau es de una impotencia absoluta, tanto que ni siquiera cuando ella le ofrezca consumar su amor querrá hacerlo para preservar el ideal. El contraste con la novela que planea -Silvio, el hijo del pescador- para recrear su relación con Madame Arnoux nos muestra la distancia entre el héroe imaginado que querría ser y lo que realmente es, entre la imaginación de sí mismo y la realidad que es el meollo de su quijotismo.

Esta quijotesca falibilidad es el tema de la famosa escena final en que él y su amigo Deslauriers reconocen su fracaso, y que es el clímax de la novela decimonónica del héroe fallido por su posición en el último capítulo y, sobre todo, por los términos en que lo hacen. Tras hacer balance negativo de sus vidas, los dos evocan un episodio que no se ha mencionado antes y que solo ahora se narra: la visita al prostíbulo de la Turca, frustrada porque Frédéric, una vez dentro y ante las risas de las prostitutas provocadas por su azoramiento, se queda paralizado y sale corriendo. Se trata, por tanto y una vez más, de una aventura fallida y, en este sentido, refleja y contiene la novela toda ya en el arranque de su acción. Pero eso que ocurría al principio de la historia Flaubert lo deja deliberadamente para el final y lo narra como un recuerdo que revelaba ya entonces un destino muy diferente del que el héroe imaginaba. Y, por si ello fuera poco, la novela concluye con el reconocimiento de ambos de que esa fue la mejor aventura de sus vidas, una auténtica epifanía no solo de un fracaso anunciado sino de su quijotesca idealización.

Hemos dejado para el final, sacrificando el discurrir cronológico de nuestro recorrido por la novela del héroe fallido, una obra en la que el quijotismo formativo no solo recupera el carácter explícito del mediador sino su contenido caballeresco, devolviéndonos así al lugar de origen del héroe quijotesco decimonónico, Walter Scott, del que se habían alejado progresivamente Stendhal, Balzac y Dickens y al que ya se acercaba Flaubert, y cerrando así el círculo. En efecto, el protagonista de la novela de George Meredith The Ordeal of Richard Feverel (1859) toma como modelo los héroes del romance caballeresco medieval, si bien de manera genérica y no individual, sin mención de obras específicas, con la significativa excepción de una oblicua referencia a una novela de Walter Scott ambientada en la Edad Media que tiene lugar en el capítulo Ix del primer volumen. Este quijotismo romántico con el que se caracteriza al protagonista en los compases iniciales de la novela encuentra primero cauce de expresión en su relación con Lucy, a la que ama y sirve con la devoción y el espíritu de los caballeros andantes por sus damas, pero luego se extiende a todo tipo de doncellas en peligro, lo que incluye a su prima Clare, a la que trata de salvar de un matrimonio sin amor, o a las mujeres caídas a las que intenta redimir de su vida desordenada o de prostitución. Y al final se proyecta en el terreno histórico propio de Scott a través de la cruzada de liberación de los pueblos europeos tiranizados, cuando Richard se imagina a sí mismo luchando a 
caballo por la liberación de Italia del yugo austríaco, aunque tal proyecto no llega a materializarse, pero sirve para caracterizarlo como un nuevo héroe quijotesco a la Waverley en ese doble territorio amoroso y militar. Pero lo que realmente completa tal caracterización es que este cambio en la orientación de su quijotismo es fruto de su inadecuación para el papel heroico que ha pretendido asumir en el ámbito amoroso, pues, mientras él se dedica a redimir a mujeres que no quieren ser redimidas y que acaban siendo la causa de su propia caída (se deja seducir por Bella Mount), su mujer está sola y expuesta al acoso de un seductor. En este sentido, podemos decidir que en esa ordalía o prueba a la que hace alusión el título juega un papel central el ordeal by love del que hablaba Buckley como una característica de los relatos de aprendizaje y que, una vez más, encarnan dos mujeres de cualidades antitéticas.

Su falibilidad en tal prueba muestra que Feverel no es el héroe romántico que imagina sino uno quijotesco por esa distancia entre imaginación y realidad que caracteriza al quijotismo decimonónico. Aquí, además, recupera ese contenido romántico y hasta caballeresco, que se hace evidente en los errores que conducen a su fracaso final. Tras su caída, su estricto código romántico le obliga a alejarse de su mujer y el mismo código, unido a un anacrónico sentido del honor que no entiende nadie a su alrededor y da a su comportamiento un algo de demencia quijotesca, le hace desafiar a Lord Mountfalcon a un duelo que acabará teniendo un trágico desenlace (curiosamente, no su muerte sino la de Lucy). Ocupado en quiméricas empresas, Richard falla en su auténtica misión, defender y proteger a la heroína (como Don Quijote es incapaz de desencantar a Dulcinea), quien, al igual que su prima Clare, es la principal víctima de su código romántico. La conciencia de esa falibilidad es subrayada por el discurso del narrador, que de manera repetida se refiere a él como hero o incluso our knight con la ironía y distancia propias de la épica burlesca, pero desde una perspectiva seria en vez de cómica. A diferencia de Edward, el desenlace trágico ni permite constatar el aprendizaje de Richard ni le da la oportunidad de evolucionar a una forma doméstica o intelectual de quijotismo que, curiosamente y al igual que en Waverley, aquí también está representado por una figura paternal, la de Sir Austin, aunque ahora situada en el origen de su quijotismo en vez del final, punto de partida en vez de llegada. El quijotismo romántico de Richard está vinculado a una inocencia generada por el sistema educativo que su padre diseńa y le aplica con el rigor y la intransigencia propias de los pedantes quijotescos en que se inspira su figura (en particular los que ejercen como pedagogos, Cornelius Scriblerus y Walter Shandy), un sistema cuya centralidad hace de este relato de aprendizaje una novela de educación ${ }^{90}$.

90 Para un análisis más detallado del quijotismo de Sir Austin, véase Pedro Javier Pardo, "El mito de Don Quijote en la novela victoriana: The Newcomes, de William Thackeray, y The Ordeal of Richard Feverel, de George Meredith", en J. Herrero y M. Morales (eds.): Reescrituras de los mitos en 
Con esta vinculación ab ovo en vez de in extremis de quijotismo formativo y monomaníaco, Meredith da un inesperado giro a la trama quijotesca generacional que veíamos en Scott y que vinculaba veteroquijotismo y novoquijotismo: al relacionarlos en sentido inverso transforma el bildungsroman quijotesco en una novela de la mala educación.

\section{El Quijote Transnacional}

La discrepancia entre creencia y acción, aspiración y resultado, imaginación y realidad, que desemboca en fracaso y desilusión, define al héroe quijotesco decimonónico, que queda así inserto en un relato de falibilidad e inadecuación algunos de cuyos exponentes más notorios acabamos de presentar. La juventud que permite enmarcar su quijotismo en un proceso de aprendizaje es una importante novedad en este nuevo tipo quijotesco y puede por ello hacer que su quijotismo pase desapercibido, por eso es tan importante el pasaje de Waverley en que Scott lo redefine como el desorden imaginativo que colora el mundo físico y real con un tinte mental o ideal. Para subrayar la naturaleza quijotesca de tal imaginación, Scott la dota de un carácter literario y romántico que formará habitualmente parte, junto con la inadecuación heroica, de la ecuación quijotesca, aun cuando sus contenidos ya no sean caballerescos (a veces ni siquiera románticos), sobre todo cuando degeneran en la mera persecución del éxito.

Scott fue uno de los novelistas más populares e influyentes del siglo XIX, no solo en el Reino Unido sino también en el resto de Europa y en América, por lo que no es de extrańar que el nuevo tipo de héroe quijotesco que cristaliza en Wavelery sea una presencia recurrente en la novela decimonónica. Aunque su literalidad se pueda ir diluyendo, los tres rasgos quijotescos que hemos aislado en esta novela son todavía reconocibles en algunas obras mayores del siglo XIX: (i) un héroe de imaginación romántica y literaria, alguien que ve el mundo como un lugar mejor de lo que es, de infinitas posibilidades, en que realizar un destino sońado y moldeado por sus lecturas; (ii) tal destino genera unas aspiraciones tan elevadas, especialmente en lo referido a su realización personal e independientemente de que esta se proyecte en un terreno caballeresco o militar, artístico o amoroso, como insuficientes son sus capacidades para llevarlas a término; (iii) y esa insuficiencia conduce a su fracaso, la pérdida de ilusiones y el descubrimiento de que no es el héroe que cree y su vida no es relato escrito en su imaginación. La difusión de estos rasgos por la novela europea del siglo XIX sitúa a Scott en una posición crucial en la evolución de la tradición cervantina, y no solo entre la novela inglesa del XVIII y la victoriana, donde comparte este papel con Jane Austen. Utilizando las ideas de Lukàcs, para quien Don Quijote es el estadio in-

la literatura. Estudios de mitocritica y de literatura comparada. Cuenca: Ediciones de la Universidad de Castilla-La Mancha, 2008, pp. 361-374. 
termedio entre la épica y la novela decimonónica de la desilusión, podemos decir que Waverley es el enlace entre esta y Don Quijote.

El modelo quijotesco formulado por Scott será determinante en una nueva concepción del quijotismo: imaginativo y formativo (pasajero, de juventud) en vez de alucinado y monomaníaco (permanente, de senectud); centrado en la inadecuación y la desilusión más que en la excentricidad y la alienación; encarnado por un héroe romántico pero fallido en vez de por un quijote antirromántico pero admirable. Este novoquijotismo es la aportación distintiva del siglo XIX, que descubre así posibilidades en Don Quijote que Cervantes no podía ni haber imaginado, sentidos que no estaban en el significado intencional cervantino. La historia de la demencia de un hidalgo manchego en las postrimerías del siglo XVI acaba convirtiéndose en una parábola de esa experiencia universal que es descubrir que no somos la persona que habíamos imaginado ser. Tal es el proceso de reinterpretación del clásico que, cuando se lleva de la crítica a la reescritura, transforma la novela en mito. $Y$ tal proceso no transciende solo el sentido primero del texto, sino sus fronteras nacionales, tanto las de la obra original como las de sus reescrituras subsiguientes: si las alemanas son decisivas en la de Scott, esta lo es en las francesas. El mito se va construyendo así sobre las aportaciones de autores sucesivos y pertenecientes a diferentes territorios lingüísticos y nacionales, cruzando las demarcaciones en las que habitualmente encerramos la literatura para acotar nuestro campo de estudio. El carácter transnacional del mito de Don Quijote cuestiona y hace inútiles -casi podríamos decir quijotescas- tales demarcaciones. 
